\title{
Polymorphism, what it is and how to identify it: a systematic review $\dagger$
}

\begin{abstract}
Jean-Pierre Brog, Claire-Lise Chanez, Aurelien Crochet* and Katharina M. Fromm*
This review on polymorphism is a personal, non-comprehensive view on the field of polymorphism - a term which is often misused. Indeed, the discussion about polymorphism and related terms is still ongoing in the area of crystal engineering. This is why we felt it timely to look into the historical development of its definition and to delimit it. A short introduction to thermodynamic aspects and characterization methods of polymorphs is given. One chapter is then dedicated to polymorphism of elements and inorganic compounds, before discussing the term for organic and organo-metallic compounds. Chosen examples are given each time to illustrate the cases of polymorphism. In the end, the conclusion yields three flow schemes useful in determining polymorphism for each compound class.
\end{abstract}

\section{Introduction}

The term polymorphism (Greek for "many forms") is, depending on the communities, associated with different

Department of Chemistry, Fribourg Center for Nanomaterials (FriMat), Chemin du musée 9, CH-1700 Fribourg, Switzerland.E-mail: aurelien.crochet@unifr.ch; Katharina.fromm@unifr.ch; Fax: +4126300 9738; Tel: +41263008732

$\dagger$ Electronic supplementary information (ESI) available: Schemes 7 to 9 are available in high resolution in supplementary material. See DOI: 10.1039/ c3ra41559g meanings. For example, in Biology, it can apply to species with different phenotypes, designating even sexual dimorphism, lipid polymorphism, nuclear dimorphism and frond dimorphism. In Computer Science, it refers to a programming language feature which allows to handle data of different types with the same interface, and in Medicine, the term polymorphism relates to a signal series seen in an electrocardiogram.

In Chemistry, and this is what we will focus on, the term means that a solid compound can adopt different forms and/ or crystal structures. The formation of a solid generally

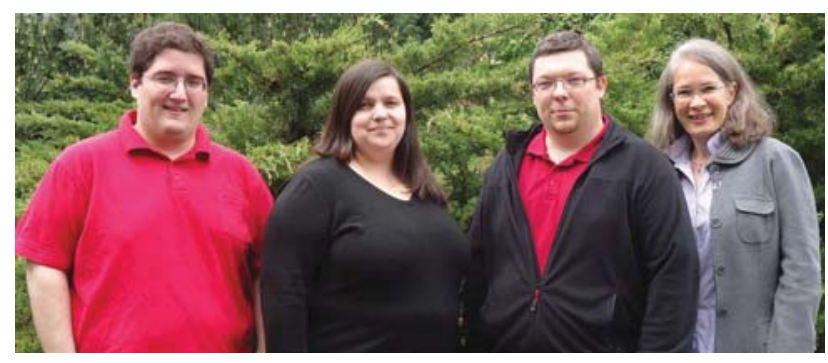

\section{Jean-Pierre Brog}

M. Jean-Pierre Brog received his MSc in Chemistry at the University of Fribourg, Switzerland, and is now studying for a PhD degree investigating the opportunities and risks of nanoscale electrode materials for Lithium-ion batteries under the supervision of the Prof. K. M. Fromm.

\section{Claire-Lise Chanez}

Ms. Claire-Lise Chanez received her MSc in Chemistry at the University of Fribourg, Switzerland, and is now studying for a PhD degree investigating the elaboration of precursors for oxide materials under the supervision of the Prof. K. M. Fromm.

\section{Aurelien Crochet}

Dr Aurelien Crochet received a MSc in chemistry at the University of Burgundy, France and in 2010 a PhD at the University of Fribourg, Switzerland under the supervision of the Prof. K. M. Fromm. He is now machine pool responsible in the Fribourg Center for Nanomaterials (FriMat).

\section{Katharina M. Fromm}

Prof. Dr Katharina M. Fromm received her Ph.D. in the field of metalorganic chemistry from the University of Karlsruhe, Germany in 1994. After postdoctoral studies in solid state chemistry at the University of Tübingen with Joachim Strähle, she joined the research group of Nobel Prize Winner Jean-Marie Lehn in Strasbourg, France before receiving her habilitation in 2002 from the University of Geneva, Switzerland. She moved back to Karlsruhe with an Emmy Noether Stipend II of the DFG, and, in 2003, to Basel, Switzerland, with an SNSF stipend professorship. In 2006, she accepted the position as full professor at the University of Fribourg, Switzerland, where she is now leading a group of ca 15 collaborators. She is currently director of the Fribourg Center for Nanomaterials and since 2010, she is been a member of the National Research Council of the Swiss National Science Foundation. 
includes a crystallization step, based on nucleation and growth. Nucleation is a kinetically controlled process during which atoms, ions and/or molecules aggregate into small clusters, first in a reversible way before forming stable nuclei. The latter are then able to grow into crystallites and crystals. It is thus easy to understand that in $\mathrm{p}$ rinciple, this first nucleation process can lead the way to different arrangements of atoms, ions and/or molecules in the solid state, depending on how the building blocks of the solid meet. Probably all scientists dealing with solid state compounds and crystals have experienced that the more one looks for new structures of a compound, the more one can find. Indeed, while interactions between ions are usually strong, the interactions between organic molecules can be numerous, and are often weak and non-directional, allowing thus for many options to combine with each other into a stable structure.

It is therefore a challenge to predict the solid state structure of a compound, and many theoretical approaches have been tested to find more and more successful predictions. For example: ${ }^{1-7}$ Indeed, the Cambridge Crystallographic Data Centre (CCDC) hosts since 1999 approximately every two to three years the Crystal Structure Prediction Blind Test, a defeat in principle for every chemist. ${ }^{5,8-11}$ The results are very encouraging, yet, Nature holds still enough surprises for us with unexpected new forms that are found in the solid state.

Polymorphism is not only interesting in the context of basic science, understanding the concepts of intermolecular interactions, but the industry dealing with materials as well as with pharmaceuticals, has also a huge stake in this area. For materials, control over the solid state is crucial for their physical properties, e.g. conductivity or tensile strength, while for pharmaceutically active compounds, the form of the solid state structure can determine its activity or even toxicity.

In March 2013, the Web of Science counts more than 66000 papers on polymorphism in the areas restricted to chemistry, pharmacology/pharmacy and materials science. ${ }^{12}$ The number of publications on polymorphism has increased dramatically from 393 in 1992 to more than 5400 in 2012, showing the interest in this research area, but also the widespread of use of the term "polymorphism" - not always with the same meaning. This is why this Review starts with a chapter on the historical development of the term, as well as the current definitions which can be found in the literature. It will then give some chosen examples out of each class of compounds, inorganic/metallic, organic and coordination compounds, in order to give the scientists first of all an idea about the types of polymorphisms which may exist, and second, a handful of tools to decide whether they have or not themselves cases of polymorphism among their own compounds. This Review is non-comprehensive.

Since the definition of polymorphism has varied greatly over time and space, let us start by unrolling the story of polymorphism and finding a definition for ourselves. We will also highlight different types of polymorphism discussed in the literature in order to include or exclude them from our personal comprehension of polymorphism.

\section{A. Polymorphism? History and definitions}

Historically, it is Klaporoth in 1788 who identified and described a first case of a compound adopting several crystal forms, namely three forms of calcium carbonate: calcite, vaterite and aragonite. ${ }^{13}$ In 1832 , the first case of polymorphism in an organic compound, benzamide, is discovered by Wöhler \& Liebig, ${ }^{14}$ but it isn't until 1938 when Robertson \& Ubbelohde find the first X-ray diffraction structure of polymorphs with resorcinol, and this is, to the best of our knowledge, the first crystal structure determination of polymorphism. $^{15}$

\section{A1. "What is a polymorph?"}

To this apparently simple question, the literature provides numerous different definitions, which are all based on the one given by McCrone in 1965: "A polymorph is a solid crystalline phase of a given compound resulting from the possibility of at least two different arrangements of the molecules of that compound in the solid state."16 In 1969, Rosenstein \& Lamy propose an alternative definition: "When a substance can exist in more than one crystalline state it is said to exhibit polymorphism.", ${ }^{17}$ which allows an interpretation including a lot of different forms, for example also solvates. Continuing the overview of the different definitions found in the literature, the one given by Burger in 1983 is noticeable: "If these (solids composed of only one component) can exist in different crystal lattices, then we speak of polymorphism." ${ }^{, 18}$ but as pointed out by Bernstein, this last definition seems to be unclear about the terms crystal lattice and crystal structure ${ }^{19}$ and the possibility of polymorphism in co-crystals, solvates or salts is excluded. The more complete definitions are probably given by (i) Sharma in 1987: "Polymorphs means the different crystal forms, belonging to the same or different crystal systems, in which the identical units of the same element or the identical units of the same compound, or the identical ionic formulas or identical repeating units are packed differently", ${ }^{20}$ or (ii) more recently by Gavezzotti in 2007 with a definition in three points: "Polymorphs are a set of crystals (a) with identical chemical composition; (b) made of molecules with same molecular connectivity, but allowing for different conformations by rotation about single bonds, (c) with distinctly different three-dimensional translationally periodic symmetry operations", ${ }^{21}$ or iii) also by Purojit \& Venugoplan in 2009: "thus it is defined as the ability of a substance to exist as two or more crystalline phases that have different arrangements or conformations of the molecules in the crystal lattice.,"22 In its recommendation of 1994, IUPAC defines the polymorphic transition as "a reversible transition of a solid crystalline phase at a certain temperature and pressure (the inversion point) to another phase of the same chemical composition with a different crystal structure.". ${ }^{23}$

Based on all these definitions, we have now a good idea of what polymorphism is, but now, it must be defined how to limit and use the term "same substance" or "compound". IUPAC, the term "chemical substance" is used for "a matter of constant composition, best characterized by the entities (molecules, formula units, atoms) it is composed of. The 
physical properties such as density, refractive index, electric conductivity, melting point etc. characterize the chemical substance." 23 This definition contains a first contradiction with polymorphs, as, indeed one of the characteristics of polymorphs is that they can have different physical properties, like for example the melting point, solubility or refractive index. For this reason, we prefer to use the term compound with the meaning of "identical chemical composition" in this Review. As a consequence, "identical chemical composition" excludes thus the phenomenon often called pseudopolymorphism - a confusing term to define solvates - from the list of possible types of polymorphism. Indeed, already in 1965, McCrone referred to pseudopolymorphism as a term “..., which is convenient to use here but which should never be allowed to come into general use, is meant a variety of phenomena sometimes confused with polymorphism.". ${ }^{16}$

We should however point out the fact that the U.S. Food and Drugs Administration (FDA) uses a wider definition for the "classification of polymorphs". "Different crystalline forms of the same substance. This may include solvation or hydration products (also known as pseudopolymorphs) and amorphous forms." ${ }^{24}$ For the pharmaceutical industry, pseudopolymorphism is a case of polymorphism, and, more surprisingly, amorphous forms are also a case of polymorphism. This broad definition allows to cover 72 different forms for axitinib, out of which five are anhydrate forms, and among the remaining 67 solvates, some co-crystals (definition see later in the chapter) are found. ${ }^{25}$

Excluding the pseudopolymorphism allowed by the FDA definition, there remain two cases of polymorphism to be considered:

The first one is due to the possible rotation about single bonds in a molecule leading to several possible conformations, thus called conformational polymorphism. Examples of conformational polymorphism in the solid state are shown in Fig. 1, top.

In the second type of polymorphism, the molecules possess quasi the same conformation, but possess different intermolecular interactions, leading to different arrangements

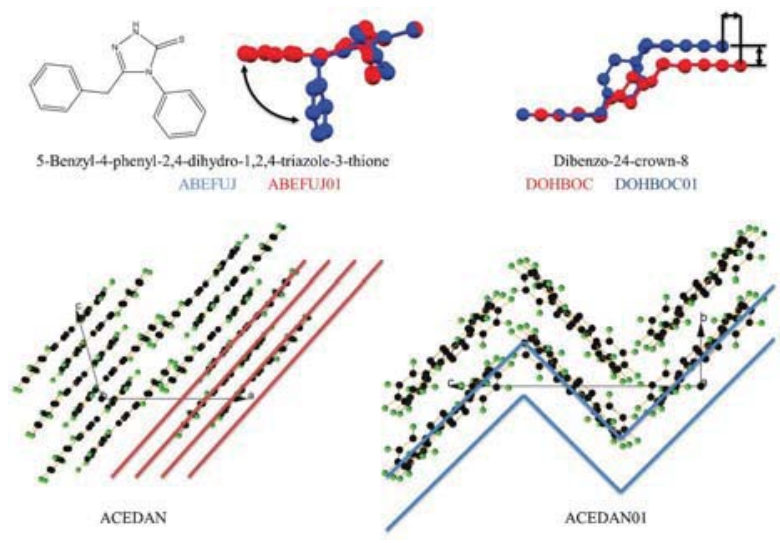

Fig. 1 Examples of conformational polymorphism. ${ }^{26-29}$ Copyright $\odot 2011$ WILEY-VCH Verlag GmbH \& Co. KGaA, Weinheim (top) and packing polymorphism ${ }^{30}$ (bottom). between the molecules. This is then called packing polymorphism. An example showing two different packings for the same compound is shown in Fig. 1, bottom.

It should be noted at this point that generally, polymorphs are numbered in the order of their discovery. Yet, the labelling does not follow a terminology rule, and on case uses a, b, c or I, II, III or $\alpha, \beta$, $\gamma$ or $1,2,3$ to name the different polymorphic forms. Further examples will be treated in more detail in the next chapters.

\section{A2. "Enantiomeric and tautomeric polymorphism"}

These two terms are commonly used but are they to be considered as real cases of polymorphism or not? Two isomers interconverting rapidly in solution may be referred to as polymorphic. Can then tautomers in the solid state also be classified as polymorphs? These ideas of rapid equilibria and interconversion are interesting, but in our chosen definition, compounds with different connectivity between the atoms of a molecule are different compounds, and hence can be called isomers, but not polymorphs.

For enantiomers, as well as tautomers, to go from one enantiomer to another, or from one tautomeric form of the second, a chemical bond needs to be broken and reassembled differently. In the case of conformational polymorphism however, simple free rotations about chemical bonds in the compounds suffice. From our point of view, enantiomeric and tautomeric polymorphism is thus not describing a real case of polymorphism. However, cases of polymorphism with the same enantiomeric or tautomeric form are of course in principle possible.

\section{A3. What is concomitant polymorphism?}

Concomitant polymorphism relates to polymorphic crystals that crystallize from the same solution AND under the same conditions, the latter of which is important and can be interpreted more or less widely. For example, in the case of crystallization per evaporation, if one set of crystals appears at the beginning of the experiment and a second set near the end, the conditions are very likely not the same as the concentration depends on the solvent volume and the quantity of compound in the solution. It is clear that any crystallization, without variation of the solvent volume, will change the concentration but small variations in the conditions could be tolerated in the discussion about concomitant polymorphs. For more details on this phenomenon of concomitance, we strongly recommend the review of Bernstein. ${ }^{19,31}$ The crystal-

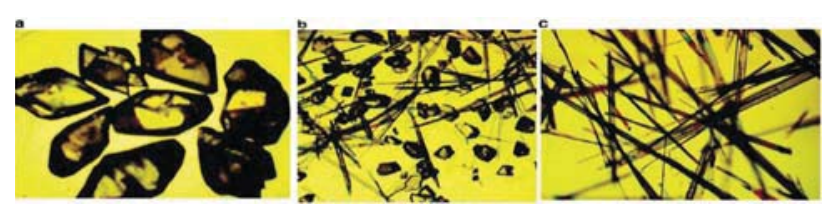

Fig. 2 (a) Morphology of form A of 3-acetylcoumarin. (b) Morphology of the form $\mathrm{A}$ and $\mathrm{B}$ at $5{ }^{\circ} \mathrm{C}$ depicting concomitant polymorphism. (c) Morphology of form B at $23{ }^{\circ} \mathrm{C}$. Reprinted with permission from. ${ }^{32}$ Copyright ${ }^{\circ} 2004$ American Chemical Society. 
lization of 3 -acetylcoumarin at $5{ }^{\circ} \mathrm{C}$ is a nice example of concomitant polymorphism (Fig. 2). ${ }^{32}$

\section{A4. What is the limit between co-crystal and pseudo- polymorph?}

Like for "polymorphism", the definition of "co-crystal", or cocrystal, is still debated in the literature. The first definition of this relatively "young" term was given by Aarkeröy ${ }^{33}$ in 2005 and will serve as basis for the coming discussion: "Co-crystals are made from reactants that are solids at ambient conditions". All extensions of this definition are focusing on the starting materials, not on the product. However, some reactants are liquid at room temperature, and if we follow Aarkeröy's definition in the case of liquid reactants, we would not observe a co-crystal, but rather pseudopolymorphs or solvates. We therefore propose to rather use the definition given by Zaworotko et al. in $2012:^{24}$ "CCo-crystals are solids that are crystalline single phase materials composed of two or more different molecular and/or ionic compounds, generally in a stoichiometric ratio, and which are neither solvates nor simple salts". This excludes co-crystallizing solvent molecules and includes liquid starting materials. It is important to point out that polymorphism exists also in co-crystals and is an important issue.

\section{A5. Why so much interest in polymorphs?}

Polymorphs are studied in many fields (chemistry, materials, pharmaceutics sciences...) for their differences in physical properties. Indeed, polymorphs can have different physical and thermodynamic properties (density and refractive index, thermal and electrical conductivity, hygroscopicity, melting points, solubility, thermal stability...), spectroscopic properties, kinetic properties (rate of dissolution, stability...), surface properties (surface area, crystal habit...), mechanical properties (hardness, compression, thermal expansion...) and chemical properties (chemical reactivity, photochemical reactivity...). For the correct design of a chemical, a material or a pharmaceutical compound, it is therefore crucial to control the solid state structure of a compound in order to guarantee its properties. Such a control may be highly relevant to life, for example in medicine with pharmaceutical compounds, or in materials science, e.g. in public transport.

One very popular example of polymorphism exhibiting different colours as a function of the structure, hence the polymorph, is the 5-methyl-2-[(2-nitrophenyl)amino]-3-thiophenecarbonitrile, initially synthesized as an antipsychotic agent, ${ }^{34}$ and also known as ROY (for Red, Orange, Yellow) (Fig. 3), ${ }^{35}$ which is probably one of the most famous and surprising compounds with respect to polymorphism. This compound has been crystallized in ten different polymorphic forms. It is not the compound with the highest number of polymorphs, but it is a spectacular compound, which illustrates perfectly the changes of physical properties. Depending on the polymorph, different colour and also different melting temperatures, varying from 94 to $115{ }^{\circ} \mathrm{C}$, are observed. For more details on this compound, refer to ref. 36

For a very well-known example of solubility differences of polymorphs, Ritonavir has to be cited (Fig. 4). ${ }^{37}$ This

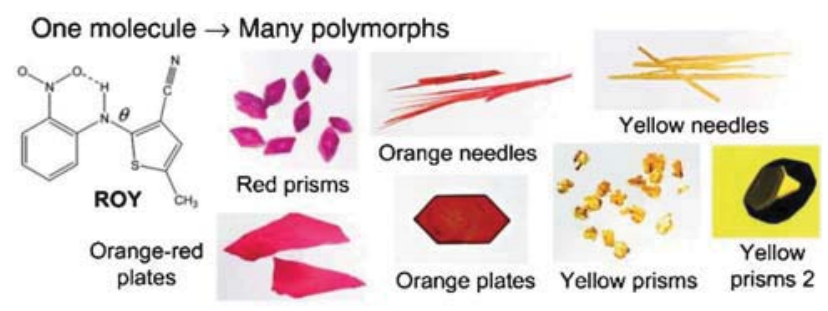

Fig. 3 Different crystal forms of ROY. Reprinted with permission from ref. 36 Copyright ${ }^{\odot} 2010$ American Chemical Society.

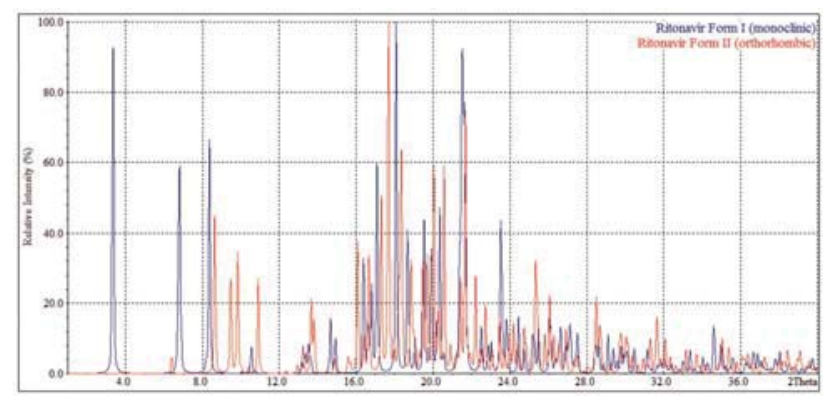

Fig. 4 Comparison of the two theoretical diffractograms of ritonavir polymorphs. (blue) Form I, (red) form II. ${ }^{38}$

compound is an antiretroviral drug, used for treating HIV infections. After its discovery in 1992 by Abbott Laboratories and FDA approval in 1996 as a semisolid capsule formulation and also as a liquid formulation, it failed the dissolution test in 1998. The precipitated form during this test was identified as new polymorph Form II, which is less soluble (Table 1) and thermodynamically more stable than Form I. The drug was finally commercialized in 1999 after approval of the two forms by the FDA. More details can be found in the paper by Bauer. ${ }^{38}$ Some other forms of Ritonavir have also been discovered but only one is another anhydrous polymorph. ${ }^{39}$

\section{A6. How to characterize a polymorph}

Characterization of polymorphs is an important issue. Nowadays, scientists have access to plenty of analytical techniques and some of them are particularly useful to characterize and determine polymorphism. We will discuss the most important ones in this paragraph.

The first technique is hot stage microscopy. This method is used to determine the transition temperature coupled with a microscope and allows us to identify changes in crystal habit as well as in light transmission, giving hints on solid state phase transitions.

Table 1 Solubility in ethanol/water $\left(\mathrm{mg} \mathrm{mL}^{-1}\right)^{40}$

\begin{tabular}{lll} 
Ethanol/water & $100 / 1$ & $75 / 25$ \\
\hline Form I & $90 \mathrm{mg} \mathrm{mL}^{-1}$ & $170 \mathrm{mg} \mathrm{mL}^{-1}$ \\
Form II & $19 \mathrm{mg} \mathrm{mL}^{-1}$ & $30 \mathrm{mg} \mathrm{mL}^{-1}$
\end{tabular}


The second technique is the thermal analysis, regrouping three techniques: differential scanning calorimetry (DSC), differential thermal analysis (DTA) and thermogravimetric analysis (TGA). DSC allows measuring melting points but also studying the transformation of metastable forms and determining the relation between the different polymorphic forms. DTA is similar to DSC, but not as quantitative. TGA allows monitoring weight changes as a function of the temperature. This technique is not useful in cases of polymorphism without changes in the degradation temperature, but is very useful for characterizing pseudo-polymorphs or solvates.

The third technique relates to spectroscopy, including very classical techniques like infrared and Raman spectroscopy to study the vibrational modes of the compound. Also, solid state NMR can be used for measuring the difference in magnetically nonequivalent nuclei in two different polymorphs.

The last family of techniques is X-ray diffraction. In this case, we can also divide the techniques in two different categories, however not - as may be expected - into powder and single crystal techniques as structure resolution is possible with both, but rather into the two categories "pattern collection" and "structure resolution". In case of X-ray diffraction pattern measurement, we consider that two samples are identical if they have the same diffractogram. Two diffractograms are considered identical when the same peaks are present $\left(2 \theta \pm 0.1\right.$ to $\left.0.2^{\circ}\right)$ and when the intensity variations of the same peaks that are smaller than $20 \%$. This latter requirement can be problematic in the case of oriented crystal growth and preferential orientation of the crystals. In order to prevent this, it is thus important to grind the materials, but with parsimony in order to avoid the increase of the peak thickness because too broad peaks can be problematic in the peak line identification. In our opinion, the most efficient method in the polymorph identification is single crystal diffraction analysis. As Dorothy Crowfoot Hodgkin argued in her Nobel lecture of 1964: "The great advantage of $\mathrm{X}$-ray analysis as a method of chemical structure analysis is its power to show totally unexpected and surprising structure with, at the same time, complete certainty".

This list of techniques is not exhaustive, and we have chosen only some popular ones. The important issue in the chosen techniques for characterizing polymorphs is to eliminate all possible doubt and for this, usually a combination of techniques is essential.

\section{A7. Thermodynamic aspects}

The nucleation and growth processes are depending on the thermodynamic properties of the compounds and their polymorphic forms. The polymorph with the lowest free energy is the most stable polymorph. This form is called the thermodynamic form and it differs from the kinetic form which is characterized by a local minimum of energy. Such a metastable polymorph is unstable from a thermodynamical point of view but it has a finite life time, which depends on its rate to transform into a more stable form and the corresponding activation energy required.

The difference in the Gibbs free energy, $\Delta G$, determines the thermodynamic stability of solids and the driving force for a transformation (at constant pressure and temperature) from
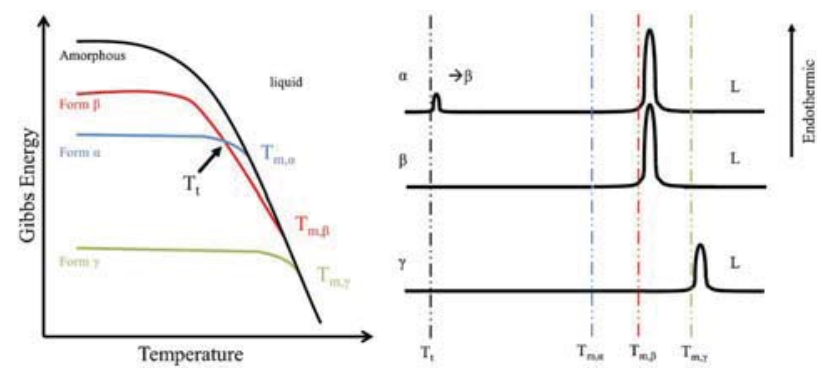

Fig. 5 Gibbs free energy diagram of three polymorphs as a function of the temperature. (Left) DSC scans as a function of the starting polymorph (right).

one polymorphic form to a second one. The Gibbs free energy is defined as the difference between the enthalpy difference and the entropy difference, as a function of the temperature, $\Delta G=\Delta H-T \Delta S$. While the enthalpy difference characterizes the differences in the lattice, hence the energy in the structure, the entropy difference is related to the lattice vibrations and the disorder. The sign of $\Delta G$ gives the relative stability of the system: if $\Delta G$ is negative, the transformation from one form to another can occur spontaneously, if $\Delta G$ is equal to 0 phases are at the equilibrium and for a $\Delta G$ positive, the transformation is not possible spontaneously or without energy input. Considering three polymorphs $\alpha, \beta$ and $\gamma$, as shown in Fig. 5, the $\gamma$-form will be the thermodynamic most stable phase. At the temperature $T_{\mathrm{t}}$ (transition temperature) both polymorphs $\alpha$ and $\beta$ have the same energy and consequently they are in equilibrium. Upon an increase of the temperature, the $\alpha$-form will transform into the $\beta$-form spontaneously. Inversely, if we have the $\beta$-form and we are on the right side of the transition point in Fig. 5, a decrease of the temperature will lead to the transformation from the $\beta$ - to the $\alpha$-form. When a pair of polymorphs like $\alpha$ and $\beta$ have a transition temperature below the melting point of the two forms, this pair is named enantiotropic. However, if a pair of polymorphs, like $\alpha$ and $\gamma$ (or $\beta$ and $\gamma$ ), has one form, which is more stable at all the temperatures below the melting point, this pair is named monotropic. In order to determine if two polymorphs are monotropic or enantiotropic, DSC or DTA can be used. For the above example, a DSC measurement with the $\alpha$-phase as starting compound will give rise to two endothermic peaks: The first one will be the transition from $\alpha$ to $\beta$, and will give the transition temperature, while the second peak will be the melting of the $\beta$-form. In contrast, starting from the $\beta$-form, only one endothermic peak will be observed, namely the melting of $\beta$. Finally, if starting from the $\gamma$-form (the thermodynamic polymorph), we will also observe only one peak, the melting of $\gamma$, whose melting temperature will be higher than the one obtained before. This experiment model does not take into account the kinetic aspects of the transition between the polymorphs, for example fast scan or low transformation rate. For more details on the thermodynamics of polymorphs, the interested reader may refer to the papers by McCrone $^{16}$ and Bernstein. ${ }^{19}$ 


\section{A8. Why this polymorph and not another? Nucleation aspects}

As experimentalists, it is sometimes difficult to understand, why, under apparently similar conditions, one, and not another, polymorph is formed preferentially, and why sometimes, this preference seems to be inverted without reason. This has to do with the nucleation processes in solution, which are reversible to a certain extend.

As said previously, the nucleation is depending on the thermodynamics, i.e. the free Gibbs energy difference between the compound in solution and the aggregated compound determines the crystallization of one form or the other. Let us consider a simple case of one compound $\mathbf{A}$ in solution in an open crystallization dish and two polymorphic forms $\mathbf{A 1}$ and A2. As time passes, solvent molecules evaporate and the solution becomes more and more concentrated. Near the saturation, molecules of $\mathbf{A}$ come closer to each other and start to aggregate. At this point, as a first option, the aggregates continue to grow and nucleation of $\mathbf{A 1}$ occurs, which will give polymorph A1; or, as second option, the aggregates redissolve and a second process of aggregation starts. This second type of aggregation, molecules of $\mathbf{A}$ arrange differently than for aggregation $\mathbf{A 1}$, and will give the nucleation of $\mathbf{A 2}$, which will give polymorph $\mathbf{A 2}$.

For more information, the interested reader can refer to papers by McCrone ${ }^{16}$ Desiraju $^{15}$ and Bernstein. ${ }^{19}$

This first chapter has now given the theory for the definition of polymorphs and related terms discussed in the literature as well as the thermodynamic bases.

We will now start with examples of polymorphism and how it can be recognized, in the three different classes of compounds, which we propose to study in this review, namely inorganic compounds, organic compounds and metal-organic coordination compounds.

\section{B. Elements and inorganic compounds}

Generally, polymorphism in inorganic chemistry is often related to different forms of the elements like the many forms of sulfur, the different carbon structures, like diamond, graphite, or fullerene or even the different phases $\alpha, \beta, \gamma$ of a pure metal (Fig. 6). In this chapter, the allotropism for pure elements will be discussed with a special focus on the cases of polymorphism. Furthermore, polymorphism for a few inorganic compounds will also be presented.

\section{B1. Allotropism, polymorphism and co.}

One of the first discoveries of "polymorphism" was in reality a form of what is still called "allotropism" (coined from Greek "other" + "to turn" = other turn, other behaviour). The allotropism concept was first used by one of the founding fathers of modern chemistry, Berzelius in $1841 .{ }^{43}$ At this time, the allotropy was used to define elements in their different forms, e.g. for sulphur, ${ }^{44}$ silicon and carbon (Fig. 6 (left) and 8).

Since this time, it has taken several different meanings: at the end of the 19th century, Lehmann stated that "the term allotropism should be used for any variation of a given
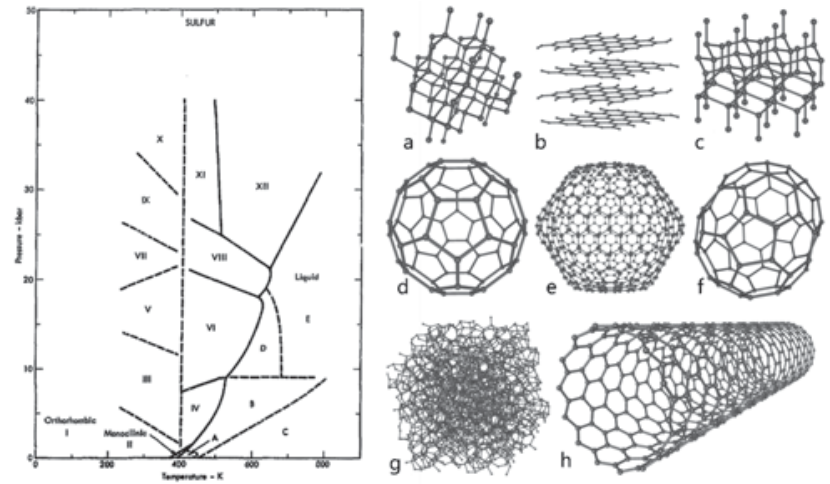

Fig. 6 (left) Phase diagram $(p, T)$ presenting most of the domains of existence of the different allotropic forms of sulfur. ${ }^{41}$ (right) Eight allotropic forms of carbon: (a) diamond, (b) graphite, (c) lonsdaleite, (d) Buckminster fullerene, (e) and (f) two other forms of fullerene, $(\mathrm{g}$ ) amorphous, and (h) nanorods of carbon. The graphene form, which is the single sheet of graphite, is missing in this scheme. ${ }^{42}$

substance, element or compound, that were ultimately traceable to variations in the substance's intermolecular organization". ${ }^{45}$ That is to say that all thermally induced changes in terms of state (liquid, solid, gas, ...) or in polymorphism (isomerism, polymerism) are a form of allotropism. ${ }^{46}$

Since then, the term "allotrope" was widely used as a descriptor for phases with identical composition. ${ }^{47}$ It evolved with the increasing knowledge and the advancement in structure determination methods.

At the beginning of the 20th century, Ostwald stated that "there is really no reason for making this distinction between polymorphism and allotropism" 48 talking about the distinction between traditional allotropy (elements only) and isomerism/polymorphism (organic/heteroatomic) for compounds of the same composition. He was for the abandon of the distinction between the term allotrope (elements only) and the term polymorph. This advice was not followed by the IUPAC and even one century later, the term "allotrope" is still in use for elements only polymorphism in most chemistry textbooks ${ }^{49}$ - and for good reasons. Indeed, in 1987, it was proposed to define: ${ }^{20}$ (i) Allotrope as the different forms of the

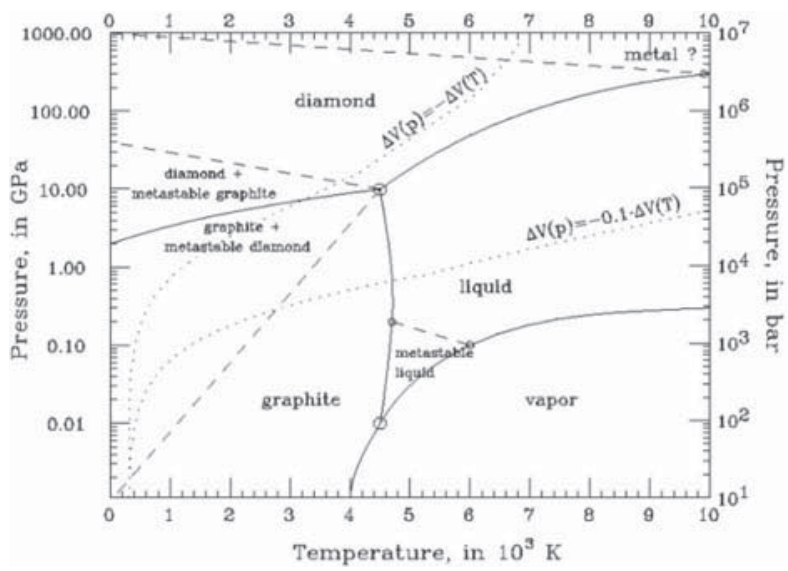

Fig. 7 Phase diagram of carbon. ${ }^{54} \odot$ CERN. 
a

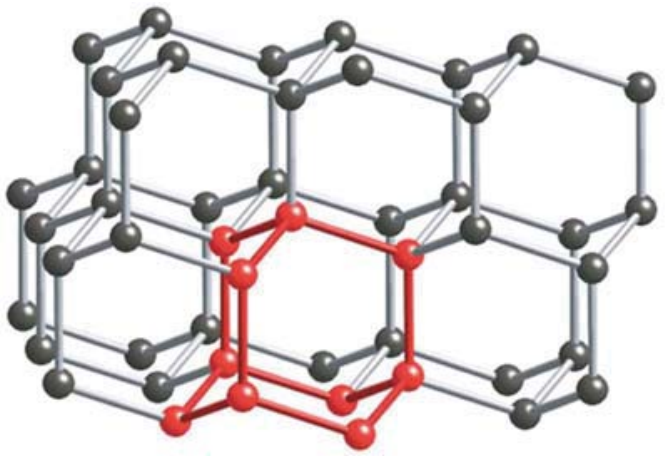

b

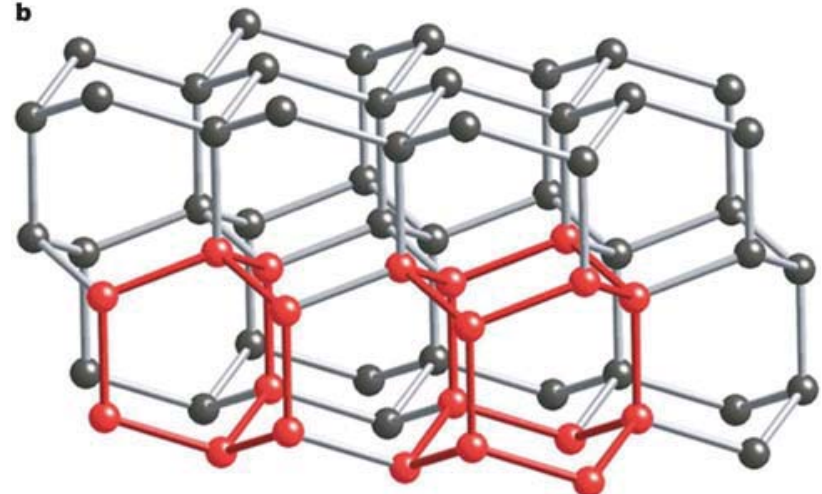

Fig. 8 Molecular structure of (a) diamond and (b) londsdaleite. Reprinted by permission from Macmillan Publishers Ltd, Nature, ${ }^{55}$ copyright ${ }^{\circ} 2003$.

same element in which the chemical bonding, and hence the connectivity, between atoms of the same element is different and may have different discrete molecular units, irrespective of the state. (ii) And polymorphs as the different crystal forms, belonging to the same or different crystal systems, in which the identical units of the same elements or the identical units of the same compound, or the identical ionic formulas or identical repeating units are packed differently.

This means that some allotropes of elements can be polymorphs, others are not. On the other hand, there are polymorphs which can refer to the same element. Hence, there is as an overlap between the classes of polymorphs and allotropes (Scheme 1).

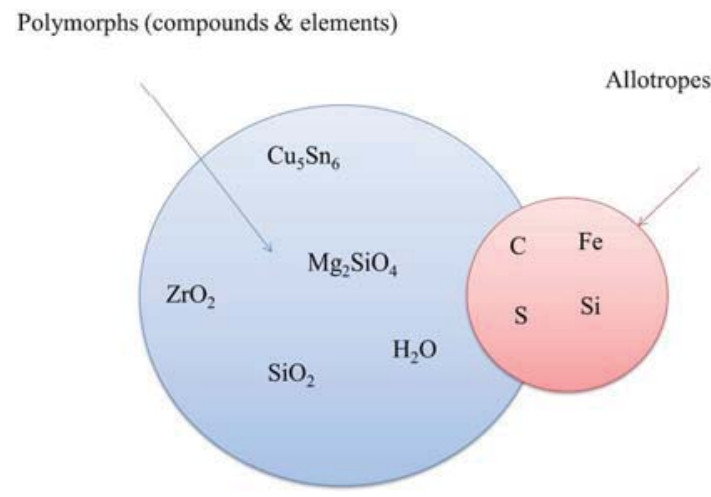

Scheme 1 Polymorphs and allotropes.
In summary the main criteria are: (i) For polymorphs: packing should be different from one crystal structure to another (comprising elements and compounds). (ii) For allotropes: the chemical bonding should be different. If the chemical bonding does not change, then it can be classified among the polymorphs (comprising elements only, independent of the state of matter).

Nowadays, allotropy is defined as:

IUPAC: The property of some chemical elements to exist in two or more different forms, known as allotropes of these elements. Allotropes are different structural modifications of an element. ${ }^{50}$

From these multiple definitions, it can be seen that the concept of allotropism has strongly evolved over time. The allotropy nowadays concerns only the different forms of an element generally inside the same state of matter (solid, liquid, gas...). Phase or state transitions of elements are not necessarily associated with modifications of the allotropic form, and for some elements, the allotropic forms can exist in several phases/states.

The term "transition" needs to be defined for allotropes and polymorphs, as it contains different aspects concerning transformation and properties:

Thus, for an allotropic transition, we have: A transition of a pure element, at a defined temperature and pressure, from one crystal structure to another, which contains the same atoms but which has different properties. ${ }^{51}$ And for a polymorphic transition: A reversible transition of a solid crystalline phase at a certain temperature and pressure to another phase of the same chemical composition, but with a different crystal structure. ${ }^{52}$

The two definitions are similar because in the first case, the criterion, i.e. the difference of physical properties, arises directly from a different crystal structure/packing. In the case of polymorphs where the crystal structure difference is the criterion, the crystal structure determines many physical properties of compounds such as the solubility, crystal shape, hardness or density. While allotrope transitions are restricted to elements, the polymorphic transition extends to compounds and hence includes that the atom connectivity should be the same - a requirement not necessarily met by allotropes.

In the following parts, some general examples of inorganic allotropes and polymorphs will be presented. The difference between an allotrope and "real" polymorphs will be shown. The importance and implications of these polymorphic and allotropic transitions on properties and applications of materials will also be made.

\section{B2. Non-metallic allotropes and polymorphs}

A systematic overview of the different types of inorganic allotropes begins with the non-metallic allotropes and the various and well-known forms of carbon. ${ }^{53}$

Carbon. Carbon presents many allotropic forms, some of which can be also considered as polymorphs (Fig. 6 (right) and 7). For example, the adamantane (diamond) belongs to the cubic system and is an allotropic form of the lonsdaleite which belongs to the hexagonal system, and it is also a polymorph according to the definition stated before: same composition, 


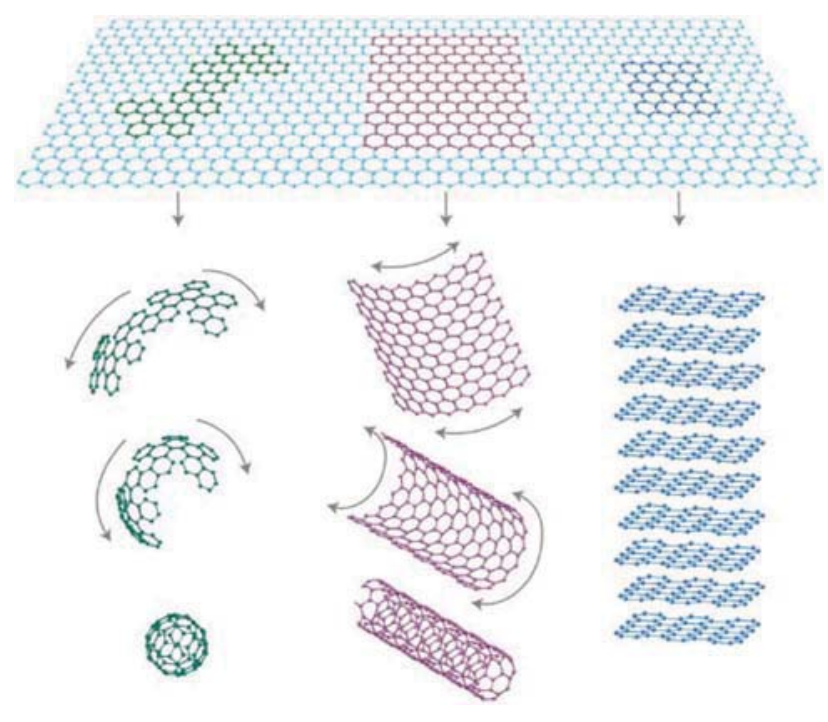

Fig. 9 Graphene as "mother" of all graphitic forms. Reprinted by permission from Macmillan Publishers Ltd, Nature Materials, ${ }^{56}$ copyright ${ }^{\circledR} 2007$.

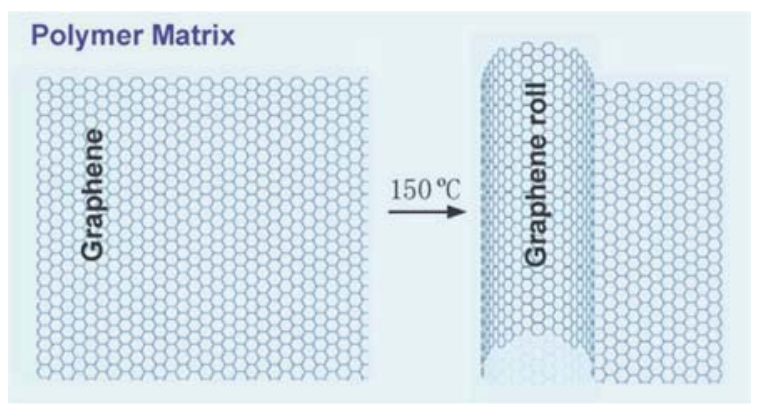

Fig. 10 Phase transition of a graphene membrane: graphene sheets, embedded in a polymer matrix, scroll and fold when heated above the polymer's glass temperature. Reprint with permission from, ${ }^{57}$ Copyright $\odot 2009$, American Chemical Society.

two crystalline forms with different packing and same chemical bonding (Fig. 8).

Starting from graphite, other forms like graphene and carbon nanorods, as well as fullerenes can be derived, which are also allotropic forms of the carbon (Fig. 9). ${ }^{56}$

All of these would in principle also fit the definition of polymorphs, as each carbon atom is always connected to three other carbon atoms. There are not a lot of studies actually focusing on transitions of these "polymorphs" mainly because they are hard to produce and isolate. One example of the phase transition of planar 2D-graphene into 3D-folded graphene has been observed optically. ${ }^{57}$ This $3 \mathrm{D}$ structure can be considered as a precursor for the formation of nanorods (Fig. 10).

It should be noted that these polymorphs are polymorphs by definition because their packing is different, while their connectivity stays the same.

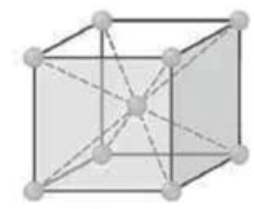

$\mathrm{BCC}$

H

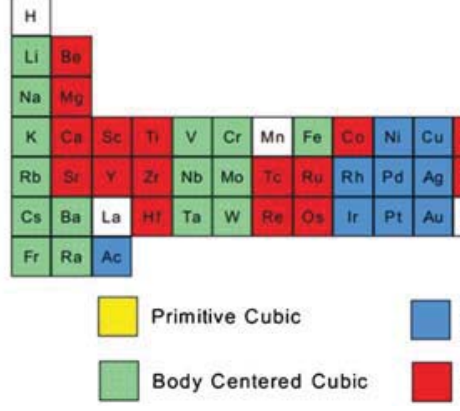

Fig. 11 Common crystal lattices of pure metals: face centered cubic (FCC), body centered cubic (BCC) and hexagonal close packed (HCP). ${ }^{60}$

\section{B3 Metallic allotropes}

Usually, pure metals adopt one of three preferential crystal lattices: body centered cubic (BCC), face centered cubic (FCC) or hexagonal close packed (HCP). These three types of crystal lattices represent the structures of $90 \%$ of the metallic elements under standard conditions. This arises from the fact that most of the metals have a coordination number of their atoms of 8 to 12 and that the structures are built using the hard sphere model to best fill space (Fig. 11). ${ }^{58,59}$

The BCC and FCC crystal structures belong to the cubic crystal system whereas the HCP belongs to the hexagonal system. In the FCC and HCP system, each metal atom is surrounded by twelve other metal atoms whereas in the BCC system, there are only eight neighbour atoms. The atom packing/density is larger in the two systems, FCC and HCP $(74 \%)$, than in the BCC one $(68 \%){ }^{58}$ In terms of polymorphism, related to atom connectivity, it would thus be reasonable to consider a transition between FCC and HCP as polymorphic transition, while the one between BCC and FCC or HCP is not. For example, in the case of the iron, the transition between the $\varepsilon$-ferrite and the $\gamma$-austenite is a polymorphic transition but the transition between $\gamma$-austenite and $\alpha$-ferrite is not (Fig. 12).

These different crystal structures have a direct impact on the metal properties. For example, lead $(\mathrm{Pb})$ and gold $(\mathrm{Au})$, which belong to the FCC lattice, are plastic metals because of the presence of a lot of planes along which rows of atoms can slide: the slip planes. In comparison, metals like titanium or cobalt, which possess an HCP structure with less slip planes, are harder to deform. ${ }^{61}$ This property of deformation of metals under stress is called the plasticity (ductility: tensile stress and malleability: compressive stress). The metal crystal structure can however change depending on the conditions, namely pressure and temperature.

Iron (Maiden): let's play metal.... A good example of such metal phase transitions is iron (Fe). The iron manufacturing 


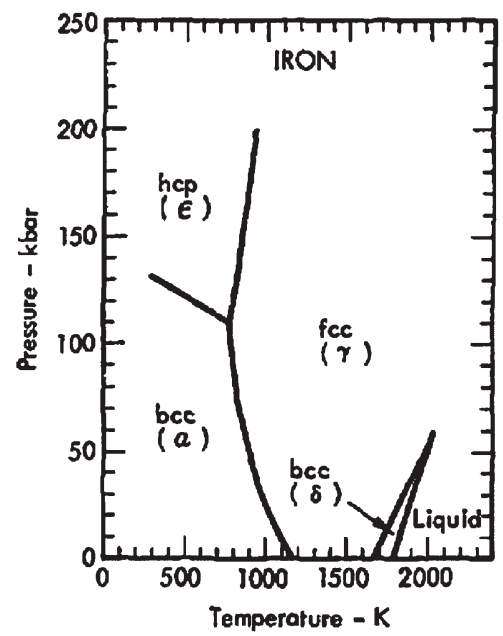

Fig. 12 Phase diagram of pure iron with different packings. ${ }^{41}$

and processing is an ancient knowledge that was passed on through the centuries. Nowadays the production of iron and its derivatives is well understood and controlled, using tools such as the phase diagram and the transition temperature point. It is a very good case study for the allotropism of metals and alloys and is also very important for the industry.

Iron adopts two different packing types upon heating: BCC $(\alpha$-ferrite) at low temperature then FCC ( $\gamma$-ferrite) upon heating, and back to a BCC system ( $\delta$-ferrite) at even higher temperature (Fig. 12). This BCC system of $\delta$-ferrite has a larger distance between the iron atoms than the one of $\alpha$-ferrite. Since the connectivity of the atoms in these two phases is the same, they are considered as polymorphs.

Several important modifications of properties arise from these allotropic/polymorphic transformations. For example, the cell volume decreases, but the density, the number of bonds between atoms and the solubility towards carbon increase from BCC to FCC. The carbon solubility is very low in the case of the BCC $\alpha$-ferrite, however in the FCC $\gamma$-austenite, it is higher due to the larger distance between the Fe atoms. Thus, the carbon can be more easily inserted into the host structure of the FCC lattice. ${ }^{62}$ By a rapid quenching of the FCC structure, doped with carbon, the BCT (body centered tetragonal) forms ( $\alpha^{\prime}$-martensite) can be obtained. The connectivity between atoms change between the FCC and BCT lattice, thus, this transformation is allotropic. The BCT, body centered tetragonal, lattice can be seen as a deformed BCC lattice. This deformed BCC lattice of iron and carbon is commonly called steel or martensite (Fig. 13).

This leads us to the subject of alloy formation, solid solutions and, in particular, steel and its processing, into which we will now make a short excursion.

Alloys/solid solutions - hard as rock: the steel!. The steel and iron industry is one of the pillars of the industrial development and has a huge economic impact on our society since the Middle Ages and even before. Its manufacturing process and development are strongly correlated with the allotropic

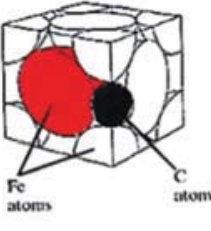

$\stackrel{F C C}{\text { Austenite: } y-F_{\theta}+C}$

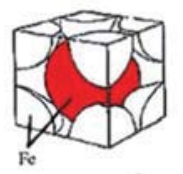

$B C C$

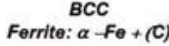

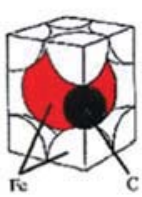

$B C T$
Fig. 13 FCC, BCC and BCT lattice system of different forms of iron with carbon insertion.

properties of the iron and its capability to solvate carbon and many other metals and additives.

One of the most important examples of the use of the properties of the iron-carbon alloy is the tempering. This ancient method is employed in forging to improve and finetune mechanical properties (hardness, toughness, ductility, ...) out of a mix of iron with low carbon content by rapid cooling (quenching) from high temperature. By using this type of technique, carbon-containing austenite $(\gamma-\mathrm{Fe}+\mathrm{C})$ can be transformed into the metastable phase of carbon-containing martensite $\left(\alpha^{\prime}-\mathrm{Fe}+\mathrm{C}\right)$ which yields a very hard steel (Fig. 13 and 14). ${ }^{63,64}$

The allotropic transformations that occur inside the ironcarbon alloy are related to the transition that we described for the iron case. In addition, in the case of theses alloys, two or more phases can coexist, for example ferrite can coexist with $\mathrm{Fe}_{3} \mathrm{C}$ (cementite), and are dependent on the total carbon content (Fig. 14). The transformations can happen following two different ways: (i) Slow transformation, which is accompanied by diffusion of atoms and the redistribution of carbon

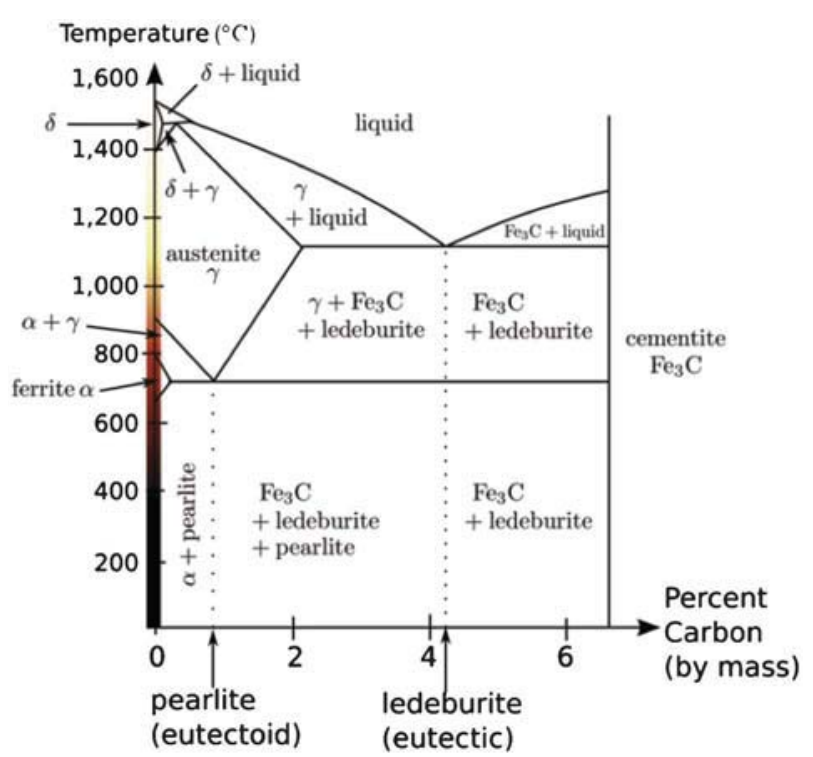

Fig. 14 Phase diagram of the Fe-C alloy phases: Ferrite: $\alpha$-Fe $+C$, Austenite: $\gamma$-Fe $+C$, Cementite: $\mathrm{Fe}_{3} \mathrm{C}$, Combination of phases: Pearlite: $\alpha$ - $\mathrm{Fe}+\mathrm{C}+\mathrm{Fe}_{3} \mathrm{C}$, Ledeburite: eutectic mixture of $\gamma$-Fe $+\mathrm{C}, \mathrm{Fe}_{3} \mathrm{C}$. The $\alpha^{\prime}$-Fe $+\mathrm{C}$ (martensite) metastable phase can be found between $0.002 \%$ and $2.1 \%$ of $C$ content below the eutectic temperature of austenite. ${ }^{65}$ 


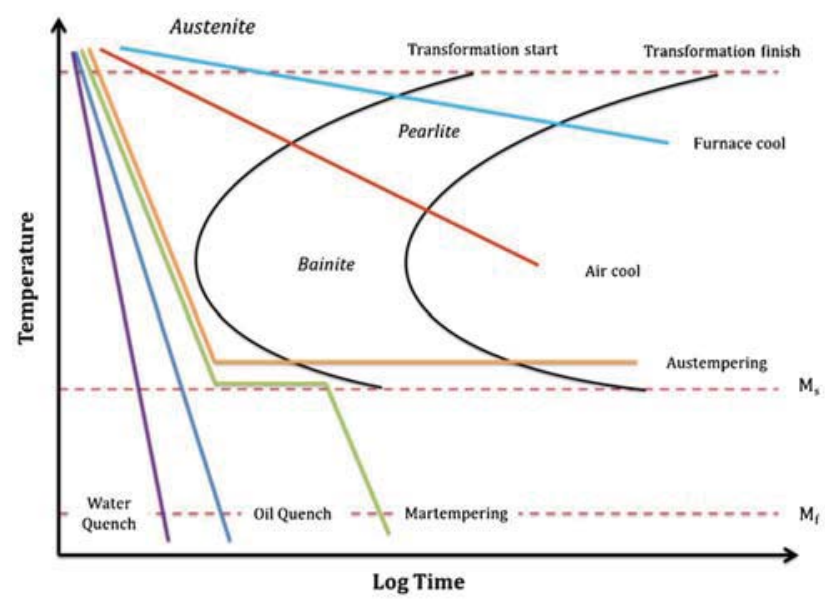

Fig. 15 Time-temperature transformation diagram or quenching diagram of steel. $M_{s}$ corresponds to the starting point of martensite formation and $M_{f}$ to the end of the formation. Pearlite: $\alpha-\mathrm{Fe}+\mathrm{C}+\mathrm{Fe}_{3} \mathrm{C}$ and bainite: a different microstructure of the pearlite. Adapted from ref. 66. Copyright ${ }^{\circledR} 1999$ Metallurgical Consultants.

between the phases, which leads to the formation of several distinct phases. The thermodynamically more stable phases are formed (slow heating/cooling). (ii) Rapid transformation, achieved by quick shear or thermal stress mechanisms, which implies a collective movement of atoms without redistribution of atoms between phases, which is called displacive transformation (supercooling). The metastable, kinetic phases can be obtained in this way. This is in essence the principle of the quenching/tempering (Fig. 15).

For the Fe-C solid solution/alloy, it has been shown that allotropic transitions have a strong impact on the final physical properties of the material: several very important properties of steel depend directly on these phenomena: solubility difference of carbon in the different phases of iron, crystal shape, the morphology and composition of grain and the physical properties, for examples plasticity, toughness or hardness depend on it. ${ }^{67}$

The 'Devil's' metal: the tin (Sn). It has been shown that the iron-carbon allotropism allows to obtain a stronger material, the steel, with tunable physical properties. In this paragraph now, the "negative" effects of allotropism on the properties of a metal will be presented on behalf of tin. Tin has a historically interesting allotropism. It is known from the antiquity and was mainly used in bronze alloys (mix of $\mathrm{Cu}$ and $\mathrm{Sn}$ ). It possesses several phases and undergoes allotropic transitions. The socalled tin pest is an allotropic transformation of white (BCT) $\beta$-Sn to grey (FCC) $\alpha$-Sn. ${ }^{68}$ The physical properties and the aspect of the white and grey tin are totally different. The white tin is ductile, metallic with a silvery shine, while grey tin is brittle, nonmetallic, darker, less smooth, and it tends to form a powder (Fig. 16).

This transition from white to grey tin occurs below $13.2{ }^{\circ} \mathrm{C}$. The kinetic of the transition is relatively slow but once nuclei of grey $\alpha$-Sn are already formed and contaminate the white $\beta$-Sn, the kinetic of conversion becomes fast, as an autocatalytic process (within several hours up to days for a total

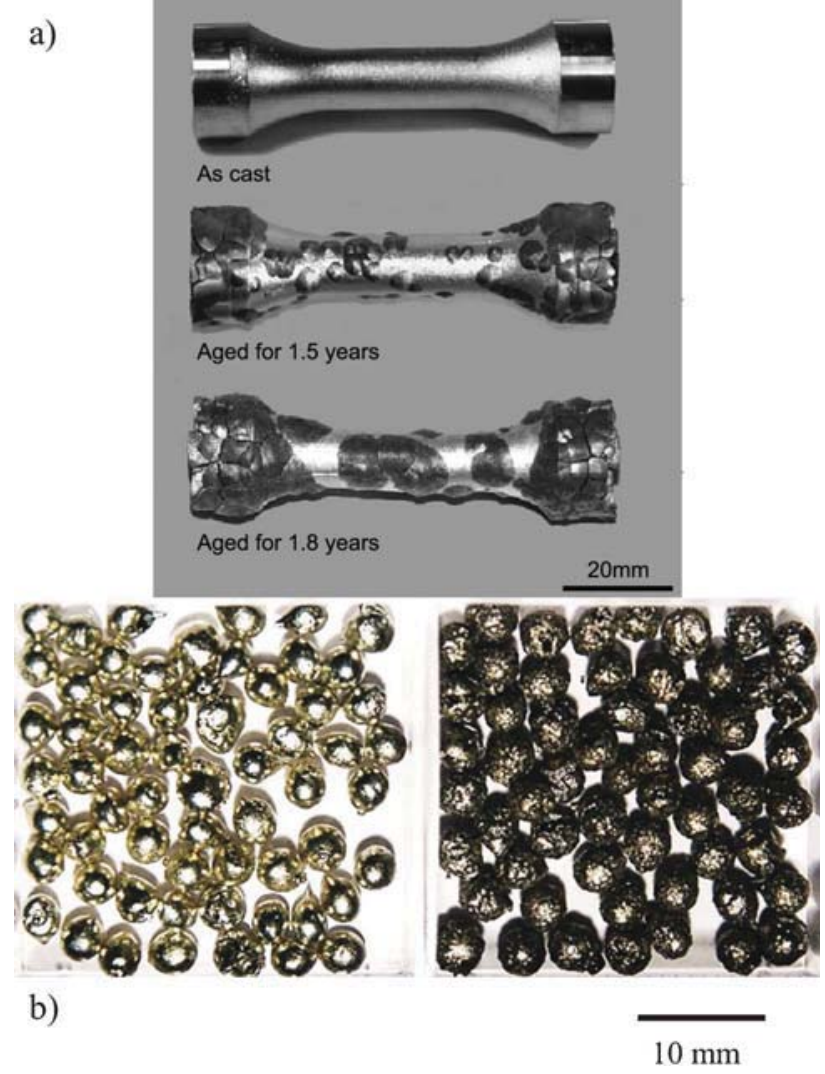

Fig. 16 (a) aging of an alloy of bronze alloy $\mathrm{Cu}_{0.5} \mathrm{Sn}_{0.5}$ stored below $13.2{ }^{\circ} \mathrm{C} .{ }^{69}$ ( Emerald Group Publishing Limited all rights reserved. (b) A representation of balls of tin: left white tin and on the right grey tin. ${ }^{70}$

conversion depending on the temperature). Even bronze (an alloy of $\mathrm{Cu}$ and $\mathrm{Sn}$ ) can undergo a similar process if prolonged storage at low temperature occurs. ${ }^{69,71}$ This transition affects mainly the tin by increasing its unit cell volume and decreasing its electronic conductivity (Fig. 17).

Some well-known stories relate the effect of this tin pest on the human activities: ${ }^{72,73}$

In 1812, the tin buttons on the clothes of Napoleon's soldiers were attacked by tin disease and crumbled in the
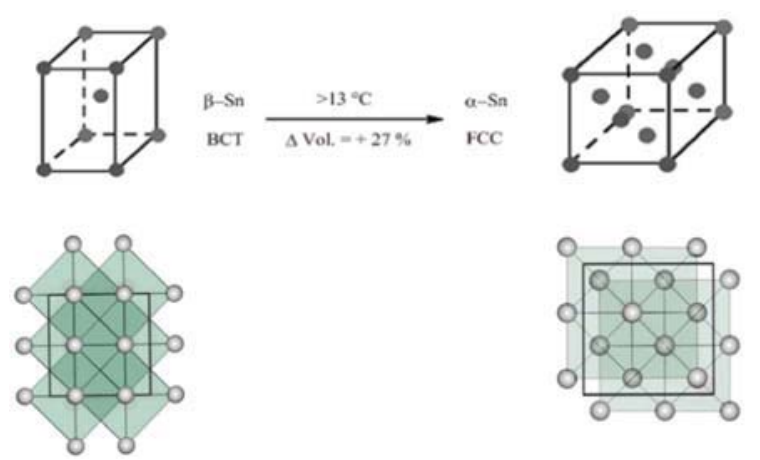

Fig. 17 Allotropic transition of tin and its effect on the unit cell. It is not considered a polymorphic transition as the number of neighbor atoms changes. 
harsh Russian winter of 1812. Napoleon was thus unprepared for the Russian winter "right down to the buttons".

In 1850, Organ pipes made of tin in the old castle church at Reitz crumbled into gray powder during the winter, one of many such occurrences in cold northern European Cathedrals. Before the chemical explanation was available, this was sometimes attributed to the work of the devil.

In 1912, Captain Robert Scott and his entire expedition to the South Pole perished. This tragedy has been attributed to an attack of tin disease. The kerosene for the return journey was stored in cans soldered with tin. The fuel escaped out of the cans resulting in the loss of all the lives to the Antarctic cold.

Even today, tin is still widely used, mainly for solder purposes. In order to fix the allotropic transition problem, some lead, bismuth and other heavy metals are now added to form stable alloys. ${ }^{74}$

From this example, we can conclude that an allotropic transition can cause important changes in properties like ductility or conductivity of materials, e.g. changing a conducting metal into an insulator. The transition in itself is in principle reversible but the structural/mechanical damages on the material are not, and integrity is completely lost as in the case of tin. A video showing the decomposition of a tin block: http://www.youtube.com/watch?v=sXB83Heh3_c.

After having discussed two cases of allotropy for metals, let us now turn towards binary compounds, for which also some examples are chosen.

\section{B4. Ceramics and minerals: the 'fake' diamond}

Zirconia-based materials are used as a simulant of gems and diamond, ${ }^{75}$ as electroceramic, ${ }^{76}$ and also for dental implants because of its biocompatibility and high fracture toughness. ${ }^{77}$ Pure zirconia, $\mathrm{ZrO}_{2}$, however, undergoes a process of unit cell expansion during its manufacturing process (sintering/heating).

The $\mathrm{ZrO}_{2}$ crystal system changes from a monoclinic crystal system at low temperature to a tetragonal one upon heating and finally ends in a cubic system at high temperature (Fig. 18). ${ }^{79}$ This volume expansion causes internal stress during the cooling process leading to cracks, fractures, and

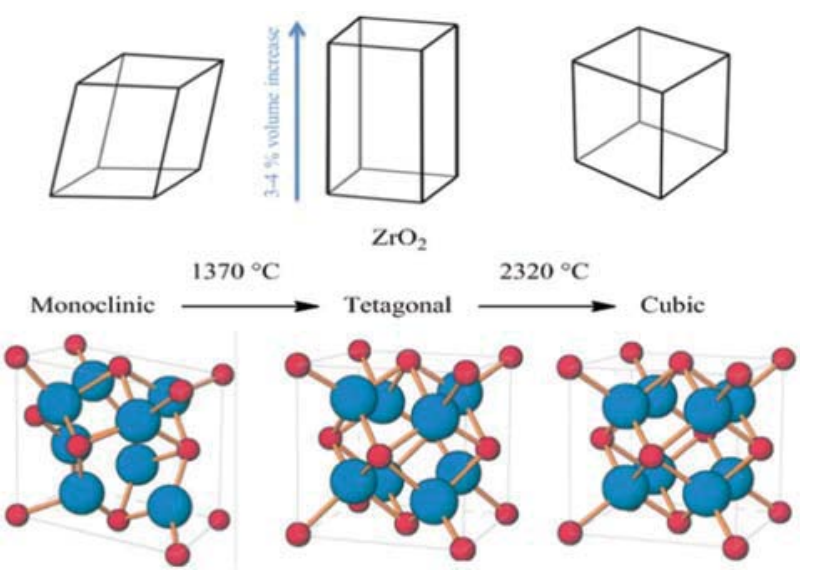

Fig. 18 Polymorphic transformation of $\mathrm{ZrO}_{2}$ : changes in lattice and crystal system view. Reprint from ref. 78. Copyright ${ }^{\circledR}$ 2004, John Wiley and Sons.

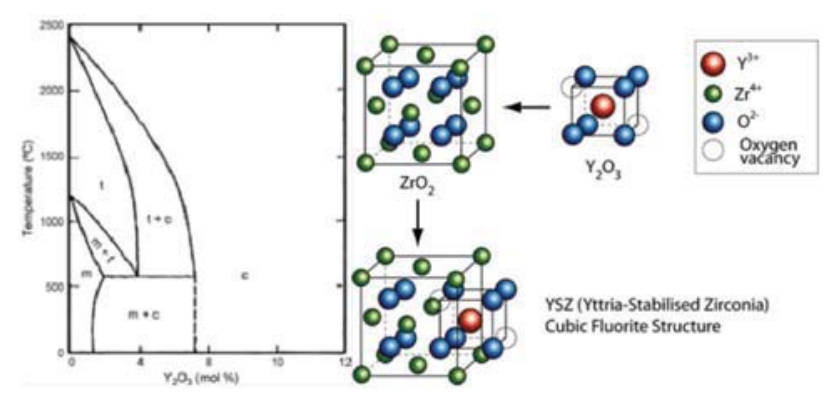

Fig. 19 (left) Phase diagram of Zirconia doped with Yttria (m: monoclinic, t: tetragonal, c: cubic), ${ }^{80}$ with kind permission from Springer Science and Business Media (right) and visual representation of the insertion of the yttrium oxide inside the zirconia oxide lattice. ${ }^{81}$

thus inhomogeneity in the material, which is therefore prone to major failure.

One solution found to prevent this was to add some yttria (yttrium oxide) and/or other oxides to the zirconia in order to fill the voids in the structure and stabilize the tetragonal metastable form or even the cubic form with a high content of dopant (electroceramics) (Fig. 19).

By doing this, a polymorphic transformation can be turned into a useful process. Thus, when cracks form in the metastable tetragonal material via an external source, the induced local stress delivers energy to the system and will trigger the polymorphic transition from the tetragonal to the monoclinic system, causing a decrease of the unit cell volume and an overall contraction of the material in the concerned stress zone. Thus, the crack, an unwanted physical default, is self-healed by the polymorphic transition and the corresponding volume reduction of the material. ${ }^{82-85}$

With the zirconia, the impact of polymorphic transformations on the properties of a simple metal oxide (ceramic) has been shown. In the following part, two examples of silicates polymorphism will be presented: the olivine and the perovskite, which play a major role in the geology and geodynamism of our planet.

\section{B5. The olivine and derivatives $(\mathrm{MgFe})_{2} \mathrm{SiO}_{4}$ and $\mathrm{MgSiO}_{3}$ : from} the crust to the core

Olivines and perovskites represent the structure type of the most abundant minerals on earth. ${ }^{86,87}$ Olivine polymorphs with the composition $(\mathrm{Mg}, \mathrm{Fe}) \mathrm{SiO}_{4}$ are mainly found under the crust of the upper Earth's mantle, while the perovskite forms of composition $\mathrm{MgSiO}_{3}$ can be found deeper in the lower mantle, down to the boundaries of the outer core (Fig. 20). ${ }^{88}$

In the upper mantle, the polymorphic transitions of olivine to more tightly packed structures can be summarized as Fig. 21.

The first polymorphic transformation of the $\alpha$ - to $\beta$-form relates directly to one of the well-known seismic discontinuities in geology and geophysics at $410 \mathrm{~km}$ of depth, corresponding to $13-14 \mathrm{GPa} .{ }^{91}$ The next transition from the $\beta$ - to the $\gamma$-form occurs even deeper at 17-19 GPa. At 23-25 GPa and $660 \mathrm{~km}$ depth, a new mineral, perovskite, and oxide are formed by the disproportionation of Ringwoodite, the $\gamma$-form 

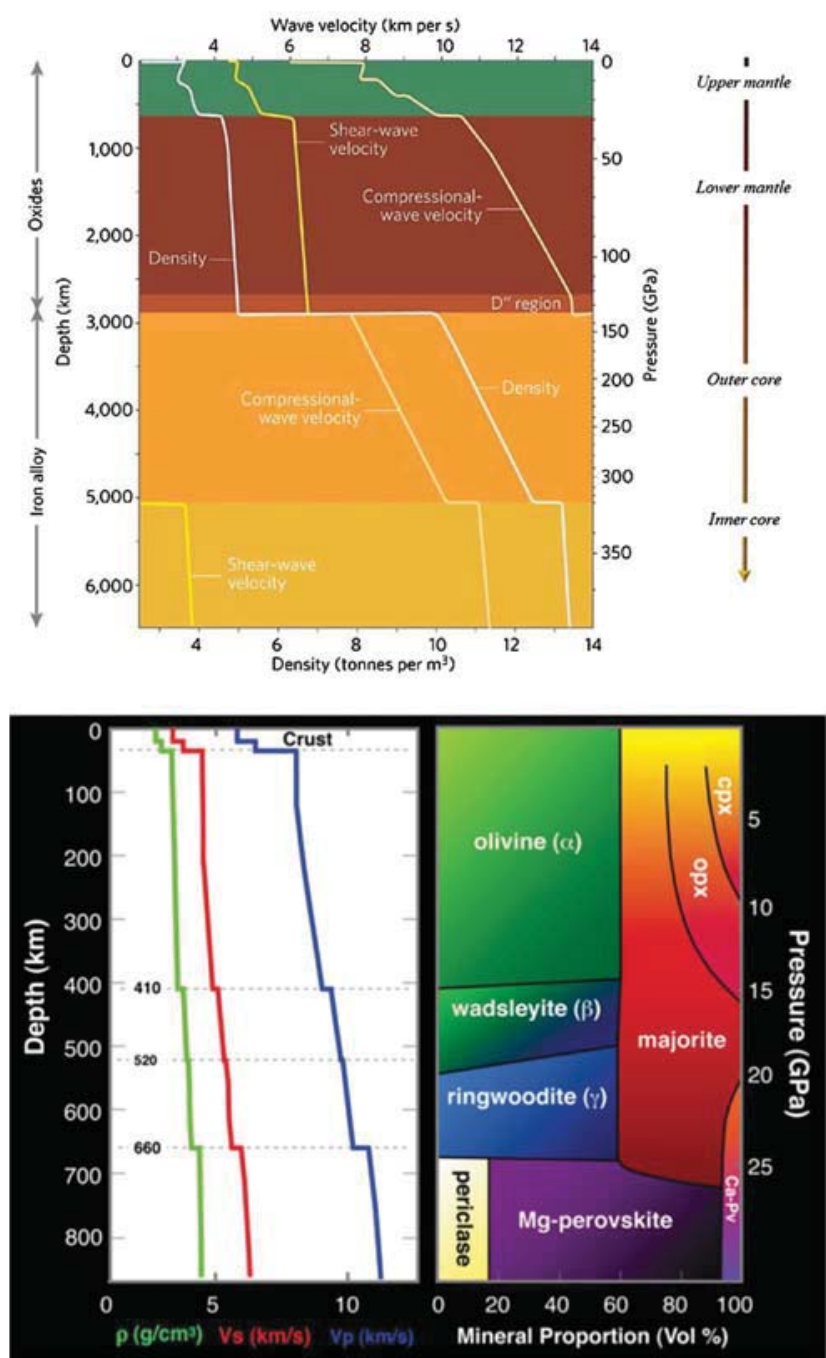

Fig. 20 Radial structure of earth (top) representation of the different layers of the earth: from the crust to the core with details on wave speed propagation, pression, depth, general chemical composition, and density (the preliminary earth model), reprinted from Publication ref. 89. Copyright $\odot$ 1981, with permission from Elsevier. (Bottom) a more detailed view: from upper to lower mantle with indications on mineral composition and seismic velocity and discontinuity. ${ }^{90}$

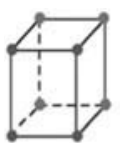

$$
\text { Primitive }
$$
orthorhombic
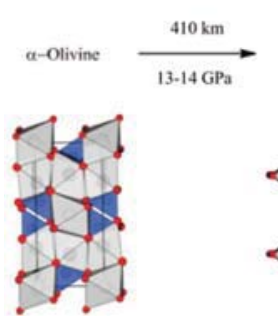
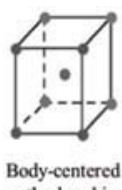
orthorhombic

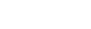

B-Wadsley
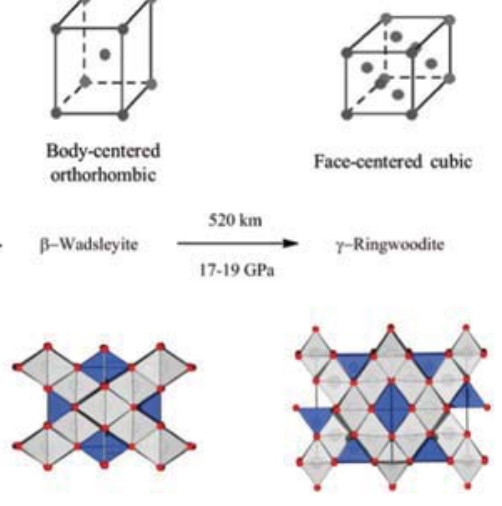

Face-centered cubic
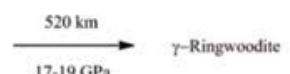

Fig. 21 The two polymorphic transitions of the olivine.

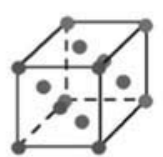

Face-centered cubic

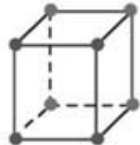

Primitive

orthorhombic

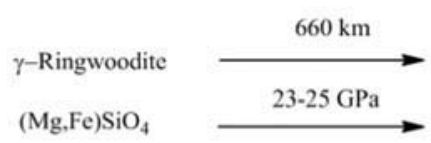

Perovskite + Oxide

$(\mathrm{Mg}, \mathrm{Fe}) \mathrm{SiO}_{3}+(\mathrm{Mg}, \mathrm{Fe}) \mathrm{O}$
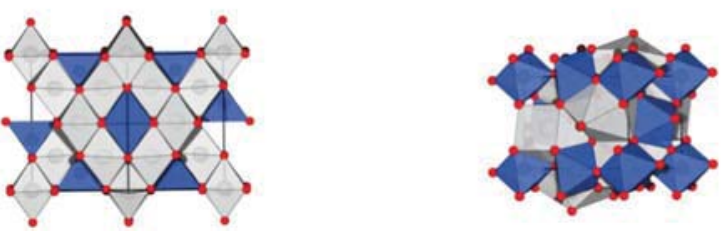

Fig. 22 Scheme of transformation of $\gamma$-ringwoodite to perovskite.

of olivine, under high pressure and temperature, corresponding to another major seismic discontinuity (Fig. 20 (bottom) and 22). ${ }^{92-94}$

The perovskite possesses also a polymorphic form. It has been proven that at even higher pressure near the mantle-core boundary conditions, the perovskite transforms into a new polymorph, the post-perovskite (Fig. 23). ${ }^{95}$ This post-perovskite has a strong influence on the third big discontinuity in the earth's mantle, the $\mathrm{D}^{\prime \prime}$ layer, a $200 \mathrm{~km}$ thick layer of postperovskite and iron doped species (Fig. 20 (top)).

These three discontinuities are considered as the main sources of the seismic phenomena and are strongly linked to the plate tectonic mechanism and also to geomagnetism by thermal coupling between the core and lower mantle. ${ }^{88,96-98}$

Silicates such as olivines are based on covalent $\mathrm{Si}-\mathrm{O}$ bonds by which each Si-atom is surrounded in a tetrahedral fashion. Another covalent compound, in which tetrahedral angles play an important role, is water.

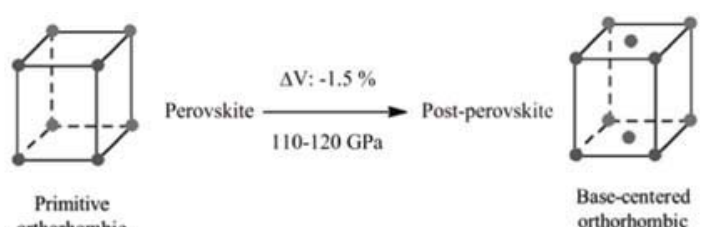

orthorhombic
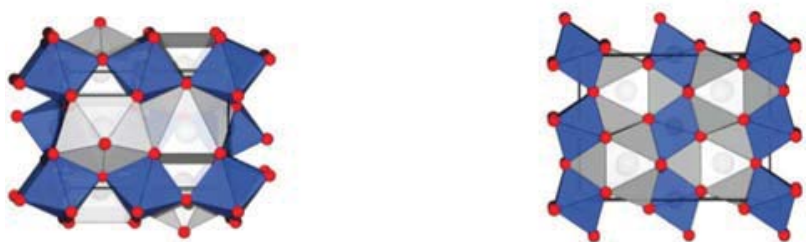

Fig. 23 Transformation of perovskite into post-perovskite. 

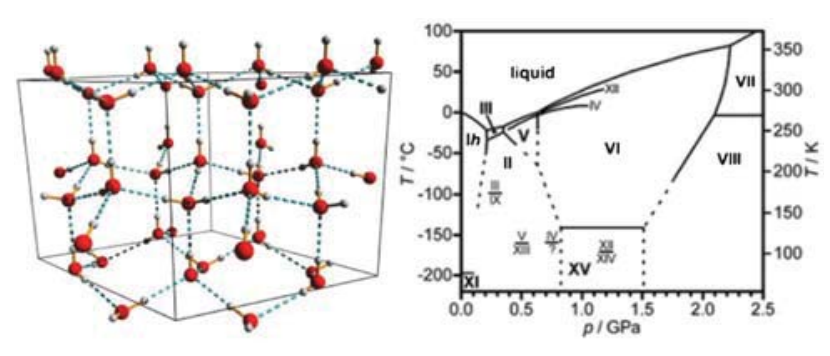

Fig. 24 Molecular structure of ice I and phase diagram of water/ice. Reproduced from ref. 101.

\section{B6. Water/ $\mathrm{H}_{2} \mathrm{O}$ : the many forms of ice}

The solid form of water is an interesting case for non-metallic compounds as it can adopt at least 15 different polymorphic forms under different temperature and pressure regimes. ${ }^{99}$ It should be noted that some of the forms of ice cannot be directly obtained from liquid water, like the forms II, IV, and VIII, which are only available through solid-solid phase transformations. ${ }^{100,101}$

The number of available structures arises directly from the molecular water structure. With a 4-coordinated structure, two hydrogen bond donor and two acceptor functions, the water packing allows the formation of a lot of possible voids available for packing rearrangements and, thus, polymorphism (Fig. 24). ${ }^{100}$

Thus, the form I of ice is the normal phase under standard pressure. There are at least two crystal systems in which it can occur: the hexagonal form (Ih), which is common for snowflakes or lake ice and the cubic form (Ic), which relates to ice formed by vapor deposition on a solid surface between $-120{ }^{\circ} \mathrm{C}$ and $-140{ }^{\circ} \mathrm{C}$. The cubic structure cannot be obtained by solid-solid transformation of the hexagonal structure using a simple cooling or compression, like it is the case for some other phases of ice. The cubic form can transform into the hexagonal one but the reverse reaction is impossible up to now. This is due to the fact that the hexagonal nuclei (and unit cells) are larger than the cubic ones. Thus during crystal growth, the cubic system is irreversibly lost. ${ }^{102}$ The cubic form possesses a slightly higher vapor pressure than the hexagonal ice form and can be formed naturally in the upper atmosphere. ${ }^{103,104}$

In conclusion, there are a lot of different polymorphic forms of ice arising from the particular molecular bonding and the space availability for packing rearrangements. This is based on a mix of covalent bonds and hydrogen bonds, the latter of which are weak, but in the solid state, where they sum up to overall large interactions, contribute significantly to the formation of these different structures. Most of these polymorphs can be distinguished by temperature and pressure limits in a phase diagram but some of them correspond only to narrow metastable forms that appear within these welldefined domains.

While water can be considered as a simple binary and inorganic compound, it is made of covalent bonds, the latter of which are at the basis of all organic compounds. Hence, our next chapter will deal with polymorphism of molecular, organic compounds.

\section{Polymorphism of organic compounds}

Polymorphism was introduced and defined in the first chapter, and in the second chapter the difference between allotropism and polymorphism has been pointed out. We will now focus on organic compounds to illustrate conformational and packing polymorphism with different examples. We will first focus on axitinib as a case of conformational polymorphism.

\section{C1. Axitinib, an active pharmaceutical ingredient (API)}

In the first chapter we have illustrated the ambiguity of some definitions, especially in the case of active pharmaceutical ingredients (APIs). In order to illustrate this, we propose here to study the case of the axitinib. This drug is approved by the FDA in case of failure of the systemic therapy in the advanced renal cell carcinoma.

The literature counts 72 forms of axitinib, of which only five are anhydrous forms, while the others are based on this compound's interesting tendency to form solvates. In the list

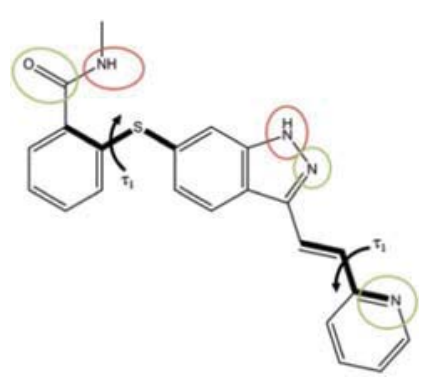

Scheme 2 Molecular scheme of axitinib. Hydrogen bond donor sites are overlaid in red, acceptor sites in green.

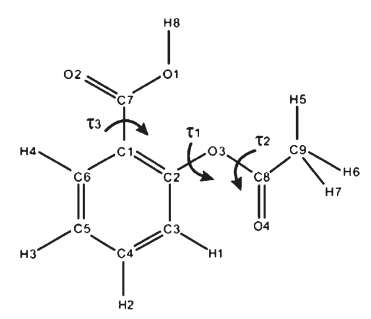

Scheme 3 Representation of the aspirin with atoms and torsion angles labeling.<smiles>CC(=O)Nc1ccc(O)cc1</smiles>

Scheme 4 Schematic representation of paracetamol. 
Table 2 Anhydrous polymorphs of axitinib

\begin{tabular}{|c|c|c|c|c|c|}
\hline Form & $\mathrm{I}^{25}$ & $I^{105}$ & $\mathrm{VI}^{25}$ & $\mathrm{XXV}^{105}$ & $\mathrm{XLI}^{25}$ \\
\hline Space group & $P 1$ & $P \overline{1}$ & $P 1$ & $P 2_{1} / c$ & $P 2_{1} / c$ \\
\hline$a(\AA)$ & $7.7400(7)$ & $11.8638(5)$ & $8.1486(4)$ & $4.5427(2)$ & $16.081(2)$ \\
\hline$b(\AA)$ & $11.8815(10)$ & $12.4067(5)$ & $10.7310(5)$ & $11.7504(5)$ & $8.0976(11)$ \\
\hline$c(\AA)$ & $12.1514(11)$ & $15.0007(7)$ & $12.6824(5)$ & $34.8339(14)$ & $15.557(2)$ \\
\hline$\alpha\left(^{\circ}\right)$ & $65.667(5)$ & $81.74(2)$ & $68.100(2)$ & & \\
\hline$\beta\left(^{\circ}\right)$ & $72.639(7)$ & $81.150(2)$ & $88.312(2)$ & $92.134(2)$ & $112.226(7)$ \\
\hline$\gamma\left({ }^{\circ}\right)$ & $76.189(5)$ & $65.985(2)$ & $70.640(3)$ & & \\
\hline Volume $/ \AA^{3}$ & 963.2 & 1984.7 & 965.1 & 1858.1 & 1875.3 \\
\hline Density & 1.333 & 1.293 & 1.330 & 1.382 & 1.369 \\
\hline $\mathbf{M P}\left({ }^{\circ} \mathbf{C}\right)$ & 210.5 & 218.7 & 211.6 & 217.2 & 225.9 \\
\hline $\mathbf{N} \cdots \mathbf{O}(\AA)$ & 2.83 & 2.80 & 2.82 & 2.83 & 2.78 \\
\hline$\tau_{1}\left(^{\circ}\right)$ & $165,2(8)$ & $174.8(8) ; 5.9(9)$ & $2.0(8)$ & $171.9(6)$ & $57.2(4)$ \\
\hline$\tau_{2}\left({ }^{\circ}\right)$ & $159.7(6)$ & $169.9(5) ; 166.3(5)$ & $172.0(4)$ & $167.9(5)$ & $5.2(4)$ \\
\hline CSD code & VUSDIX06 & VUSDIX01 & VUSDIX03 & VUSDIX & VUSDIX04 \\
\hline
\end{tabular}

of solvated forms, some contain the same solvent, e.g. water, cyclohexanone, acetic acid, isopropyl alcohol, and ethanol, but in different amounts, and are thus rather pseudo-polymorphs or solvates. We will focus here only on the anhydrous forms.

The scheme of axitinib (Scheme 2) shows that two potential hydrogen bond donor and three potential acceptor groups exist in this molecule. All of the five polymorphs (Table 2) possess hydrogen bonds between the pyrazole (donor) and the benzamide (acceptor). However, polymeric forms I and VI have also hydrogen bonding motifs between the benzamine as donor and the pyrazole as acceptor, whereas forms IV, XXV and XLI form hydrogen bonds between the benzamine, also as donor, and the pyridine as acceptor (Fig. 25).

A simple method to compare the polymorphs, especially the conformations of the axitinib molecule itself, which allow these different forms, is to overlay the molecular units of each
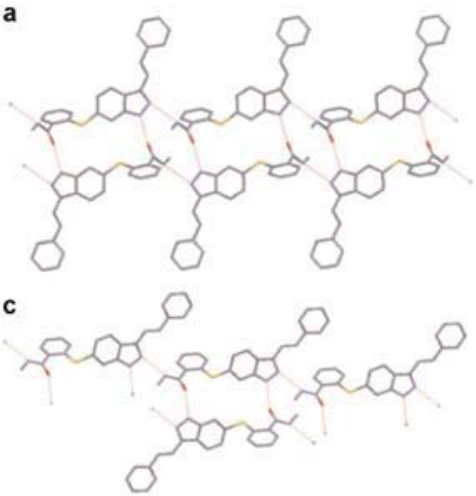

e

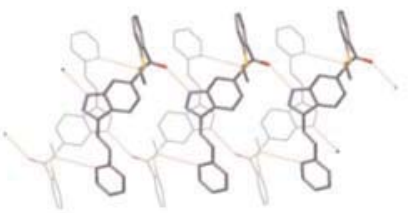

b

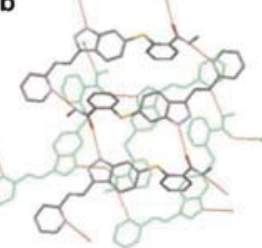

d

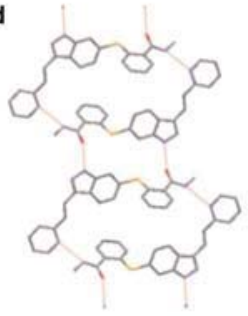

Fig. 25 Crystal packing patterns of anhydrous axitinib forms: (a) form I, (b) form IV, (c) form VI, (d) form XXV and (e) form XLI. H-bonds are drawn as dashed red lines. Reprinted with permission from. ${ }^{25}$ Copyright $\odot 2010$ Wiley-Liss, Inc.
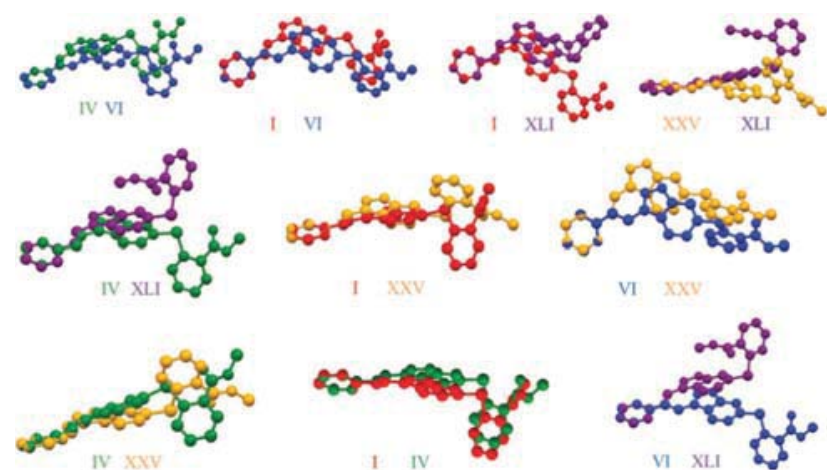

Fig. 26 Aligned crystallographic molecular conformations of axitinib (form I is in red, IV in green, $\mathrm{VI}$ in blue, XXV in orange and XLI in purple).

of the different crystal structure. Campeta ${ }^{25}$ carried out this study and found that we are in presence of conformational polymorphism. Indeed, if the pyridine group is superposed for each form, the rest of the molecule is not aligned for each polymorph (Fig. 26). This visualization is completed by a comparison of the torsion angles in the molecules for each polymorph (Table 2).

Based on these differences in the conformation, different hydrogen bonds are available, and different packings derive from these conformational changes.

Table 3 Crystallographic data for the polymorphic forms of TNT

\begin{tabular}{llll}
\hline & Monoclinic & Monoclinic & Orthorhombic \\
\hline Space group & $P 2_{1} / a$ & $B 2 / c$ & $P c a 2_{1}$ \\
$\boldsymbol{a}(\AA)$ & $14.9113(1)$ & $39.81(5)$ & $14.910(2)$ \\
$\boldsymbol{b}(\AA)$ & $6.0340(1)$ & $6.05(1)$ & $6.034(2)$ \\
$\boldsymbol{c}(\AA)$ & $20.8815(3)$ & $14.96(5)$ & $19.680(4)$ \\
$\boldsymbol{\beta}\left({ }^{\circ}\right)$ & $110.365(1)$ & $90.3(5)$ & 90 \\
Volume $\left(\AA^{3}\right)$ & $1761.37(4)$ & 3607 & $1770.6(7)$ \\
Temp. $(\mathbf{K})$ & 100 & & 123 \\
$Z$ & 8 & & 8 \\
CCDC code & ZZZMUC08 & & ZZZMUC09
\end{tabular}


Table 4 Comparison of torsion angles $\left(^{\circ}\right)$ in the monoclinic and the orthorhombic polymorphic forms of TNT

\begin{tabular}{lllll}
\hline Nitro & Monoclinic & & \multicolumn{2}{c}{ Orthorhombic } \\
\hline & A & B & A & B \\
2 & $51.9(1)$ & $38.0(1)$ & $39.7(4)$ & $52.9(3)$ \\
$\mathbf{4}$ & $22.6(1)$ & $33.5(1)$ & $33.7(4)$ & $22.7(4)$ \\
$\mathbf{6}$ & $44.8(1)$ & $58.7(1)$ & $58.3(3)$ & $44.4(6)$ \\
\hline
\end{tabular}

Axitinib is a good example of conformational polymorphism with big differences in the torsion angles. The second example of this chapter is not an API but an explosive, the 2,4,6trinitrotoluene, this small and simple molecule will be treated as example of packing polymorphism, while the conformation of the molecule itself does not change much.

\section{C2. 2,4,6-trinitrotulene (TNT), an explosive polymorph}

Originally used as a yellow dye, TNT was discovered by Wilbrand in $1863^{106}$ and used as explosive in the 1900s. Its energy density of $4.184 \mathrm{MJ} \mathrm{kg}^{-1},{ }^{107}$ is used as standard for other explosives. Despite a not so great appreciation at the beginning, TNT is now one of the most popular and widely used explosive compounds. The great advantage of this material is its large temperature range of stability. This wide temperature range is important for the preparation and the handling in civil (demolition work) and military use. Nevertheless, in 1950, Ito claimed that three phases of TNT exist, one orthorhombic and two monoclinic ones (Table 3). ${ }^{108}$ After long studies, two polymorphs are today listed, a monoclinic and an orthorhombic one. ${ }^{109}$ TNT melts around $82{ }^{\circ} \mathrm{C}$, and liquid TNT can be poured into containers without risk of explosion. However, pouring a melt or a solution of a compound able to crystallize in different forms can be problematic. One major property for an explosive material is the sensitivity to detonation. In order to control if one polymorph is more stable versus detonation than the other one, it is important to study the polymorphism of this compound for a safe utilization.

Each molecule of TNT possesses three nitro groups able to adopt multiple torsion angles with respect to the aromatic mean plane. In order to determine if we are in presence of conformational or packing polymorphism, these torsion angles need to be compared. Both structures possess two<smiles>Cc1c([N+](=O)[O-])cc([N+](=O)[O-])cc1[N+](=O)[O-]</smiles>

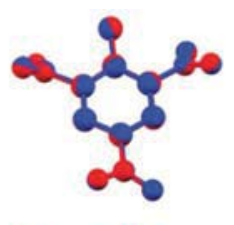
Monoclinic A
With Orthorhombic B

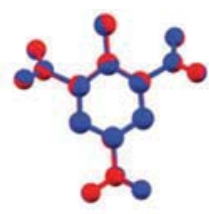

Monoclinic B

With

Orthorhombic A
Fig. 27 Overlay of the two molecular units (unit A from the monoclinic form (in red) with unit $B$ from the orthorhombic from (in blue) and unit $B$ from the monoclinic form (in red) with unit A from the orthorhombic from (in blue).
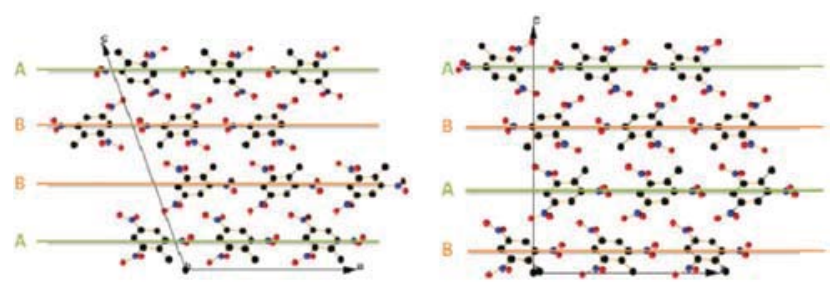

Fig. 28 Representation of the unit cells of the two polymorphs of TNT. H atoms are omitted for clarity.

asymmetric units A and B. Unit A of the monoclinic form is composed by the atoms $\mathrm{C} 8$ to $\mathrm{C} 14$ ( $\mathrm{C} 1$ to $\mathrm{C} 7$ for unit $\mathrm{B}$ ) and in the orthorhombic form by atoms C1 to C7 (C8 to C14 for unit B). A comparison of the torsion angles (Table 4) shows that some slight differences are present, but one can still easily superpose the monoclinic A unit with the orthorhombic B unit (and monoclinic B with orthorhombic A) and the difference is shown to be not very large (Fig. 27). One can conclude that despite three free rotational nitro groups in the structure, and two distinct units, it is not a case of conformational polymorphism. Hence, it should be a packing polymorphism.

In order to validate the case of packing polymorphism, the difference in the two packing modes becomes evident by a simple visualization of the packing (Fig. 28). Indeed, still using these two units A and B, in both structures unit A and unit B are arranged in line with their identical units, and these lines are formed by a glide/translation operation (along the $a$ direction). Nevertheless, the repetitive arrangements of the lines in the unit cell are different. In the monoclinic form, an alternation of $\mathrm{ABAB}$ lines is achieved, while in the orthorhombic form, it is an ABBA arrangement. This succession of two lines of $\mathrm{B}$ is due to the presence of a two-fold rotation axis symmetry operation.

The knowledge of these two crystal structures is helpful for better understanding this case of polymorphism, but not enough to determine if one polymorph is more dangerous
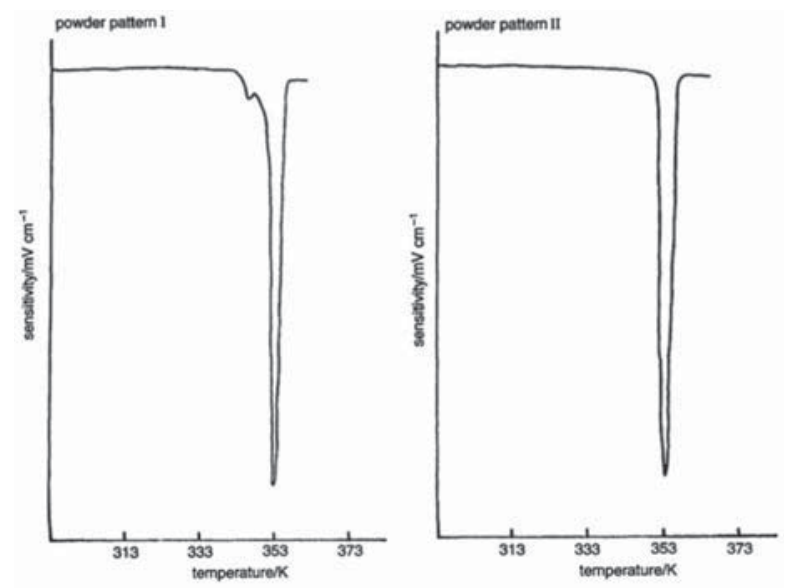

Fig. 29 Typical DSC traces for (a) orthorhombic and (b) monoclinic TNT. Reprinted with permission from. ${ }^{110}$ Copyright ${ }^{\odot} 2003$, American Chemical Society. 
Table 5 Comparison of the two aspirin polymorphs obtained by Desiraju ${ }^{119,120}$

\begin{tabular}{|c|c|c|c|}
\hline Form & I & II & IIPZ \\
\hline Space group & $P 2_{1} / c$ & $P 2_{1} / c$ & $P 2_{1} / c$ \\
\hline$a(\AA)$ & $11.2776(2)$ & $12.1515(10)$ & $12.095(7)$ \\
\hline$b(\AA)$ & $6.5517(1)$ & $6.5064(5)$ & $6.4991(4)$ \\
\hline$c(\AA)$ & $11.2741(2)$ & $11.3677(9)$ & $11.323(6)$ \\
\hline$\beta\left(^{\circ}\right)$ & $95.837(1)$ & $111.574(3)$ & $111.509(9)$ \\
\hline Volume $/ \AA^{3}$ & $828.70(2)$ & $835.79(12)$ & $827.1(8)$ \\
\hline Temp. (K) & $123(2)$ & $180(2)$ & $100(2)$ \\
\hline$R(\%)$ & 2.55 & 2.9 & 10.8 \\
\hline$\tau_{1}\left({ }^{\circ}\right)$ & $82.2(1)$ & $83.9(2)$ & $84(2)$ \\
\hline$\tau_{2}\left(^{\circ}\right)$ & $3.9(1)$ & $3.7(2)$ & $5(2)$ \\
\hline$\tau_{3}\left(^{\circ}\right)$ & $1.8(2)$ & $1.3(2)$ & $2(1)$ \\
\hline $\mathbf{D} \cdots \mathbf{A}(\AA)$ in dimer & $2.641(1)$ & $2.635(2)$ & $2.63(1)$ \\
\hline Melting point $\left({ }^{\circ} \mathrm{C}\right)$ & 143.9 & 135.5 & 135.5 \\
\hline CSD Code & ACSALA14 & ACSALA15 & ACSALA13 \\
\hline
\end{tabular}

than the other. To determine which form is the more stable one, some tests have been performed by e.g. DSC measurements. The DSC traces shows in the two cases an endothermic peak at $84{ }^{\circ} \mathrm{C}$ corresponding to the melting of the TNT, but in the case of the orthorhombic TNT (Fig. 29), one can also observe another endothermic peak a few degrees below the melting point. This peak corresponds to the transformation of the orthorhombic phase into the monoclinic phase. From these measurements, it can be concluded that an enantiotropic couple of polymorphs is present and that the monoclinic phase is the more stable one. Calculations show that the energetic difference between the two lattices is $c a$. $0.6 \mathrm{kcal}$ $\mathrm{mol}^{-1} \cdot 110$

As mentioned previously, earlier studies have identified three phases: two monoclinic and one orthorhombic phases. ${ }^{108}$ After studies of crystallization in different solvents and Laue diffraction on these different crystals, Gallagher and Sherwood have reported that the second monoclinic unit cell found by Ito was in reality a monoclinic twin crystal. The twins are related by a rotation around an axis perpendicular to the plane (100). ${ }^{111}$

For more details on polymorphism of TNT, see ref. 110, 112115.

The second example of packing polymorphism is again an API, namely aspirin. This simple compound is used and has interested the scientific community for a long time. Recently, the discussion was vivid in the literature, when a new form of aspirin was claimed to be found, as we will discuss in the following.

\section{C3. Aspirin, so old and so new}

Acetylsalicylic acid, aspirin, was first synthesized and isolated by Hoffman in 1897 (Scheme 3). ${ }^{116}$ However, aspirin has been used for a long time, as the compound is extracted from plants, especially from willow and spiraera. From the antiquity, this compound is known to help relieve pains, fevers and headaches. A description for its decoction from 3200 BC has been found in the Ebers papyrus from 1550 BC. Hippocrates also described the use and properties of powders made from Willow bark and leaves.

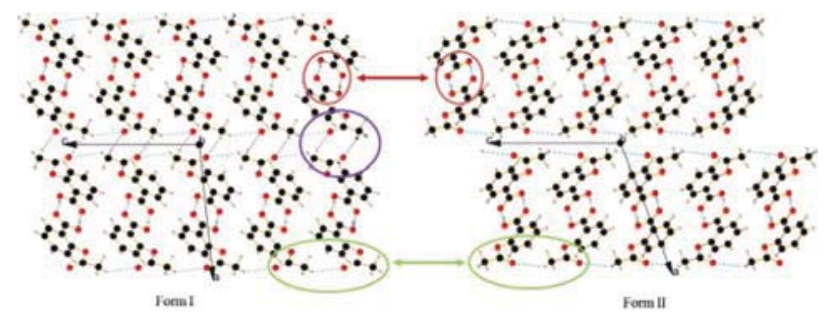

Fig. 30 Packing of the molecular structure of the two polymorphs of aspirin, form I (left) and from II (right). Hydrogen-bonds are drawn as blue dashes or plum lines. Red circles show the $\mathrm{R}_{2}^{2}(8)$ motif, green circles the $\mathrm{C}(4)$ motif and the plum circle the $\mathrm{R}_{2}{ }_{2}(8)$ motif.

The first crystal structure of aspirin was reported by Wheatley in $1964,{ }^{117}$ while in 2005 , Peterson and Zaworotko reported a new structure for this compound. The first new form by Peterson and Zaworotko (IIPZ) crystallizes in the monoclinic space group $P 2_{1} / n$ with an R-value of 10.8 . Since then, many other resolutions of the same phase were reported. ${ }^{118}$ In order to best compare the unit cells found for the two forms, the ones determined with similar $R$ value will be used, hence the one based on the crystal data of Desiraju. ${ }^{119,120}$ From Table 5, it can be seen that the two polymorphs have the same space group but clearly different unit cells. Comparing the molecular geometry of the two forms, slight differences in terms of torsion angles are observed. The dimer ${ }^{121}$ formed by the hydrogen bonds between the carboxylic groups remains intact with a graph set $\mathrm{R}_{2}^{2}(8)$ (red circle in Fig. 30). ${ }^{122}$ The two forms have also the same hydrogen bonds between the methyl group (C9) and the $\mathrm{O} 4$ of the acetyl group forming a C(4) chain (green circle in Fig. 30). These two hydrogen bonds form a succession of $\mathrm{C}(4) \mathrm{R}_{2}^{2}(8)$ motifs, hence a chain of dimers. However, one can detect a simple but important difference in the hydrogen bonding motifs. This difference is a third hydrogen bond in form I, based on a $\mathrm{R}_{2}^{2}(8)$ motif (plum circle in Fig. 30), which connects the dimer chains $\mathrm{C}(4) \mathrm{R}^{2}{ }_{2}(8)$ together to form a $2 \mathrm{D}$ hydrogen-bonded sheet structure, which is absent in form II.

After the first publication of the form II of aspirin, the problem of data quality has been raised. Indeed, the reported crystal structure had bad parameter values $\left(R 1_{\mathrm{obs}}=0.162\right.$, $w R 2_{\text {obs }}=0.308,2 \theta_{\max }=40^{\circ}$ ) and no anisotropy refinement. These values created a debate discussing the question if that "new" form was real or a determination error of the unit cell. This example points out the fact that, in polymorphism, and in general in Science, one technique is usually not enough to determine and prove with certainty that a new polymorphic form is observed. Spectroscopic methods and thermal analyses are also possible and should be used to fully characterize the compound (see first chapter for list of possible analytic techniques).

For more details on the polymorphism of aspirin see ref. 118-120, 123, 124.

To conclude this part on organic compounds, a last organic compound, an API, will illustrate that X-ray single crystal diffraction is not the only possible tool and shows that a combination of different tools is important. 


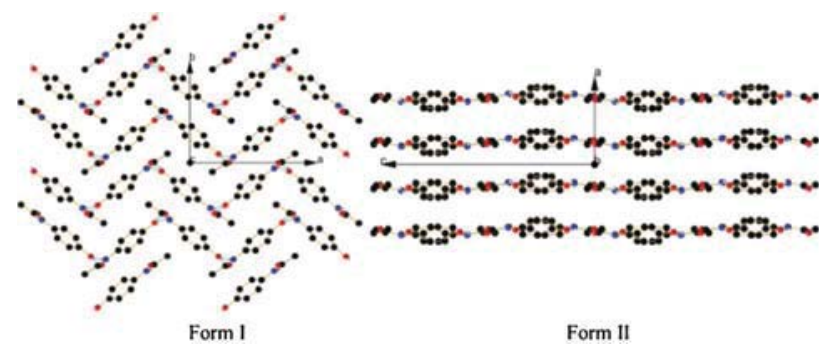

Fig. 31 Packing of the form I and II of the paracetamol, some hydrogen atoms are omitted for clarity.

\section{C4. Paracetamol: PXRD and DSC as tools}

The acetaminophen, or paracetamol (the name comes from letters of each part of the scientific name: para-acetylaminophenol) is a very commonly used drug as analgesic and antipyretic (Scheme 4). This drug is commonly known to have two polymeric forms I and II, one monoclinic (I) and one metastable orthorhombic form (II). The two crystal structures are known since $1976^{125}$ and $2004,{ }^{111}$ but in 1982 , Burger has mentioned the existence of a highly metastable form III. ${ }^{126}$
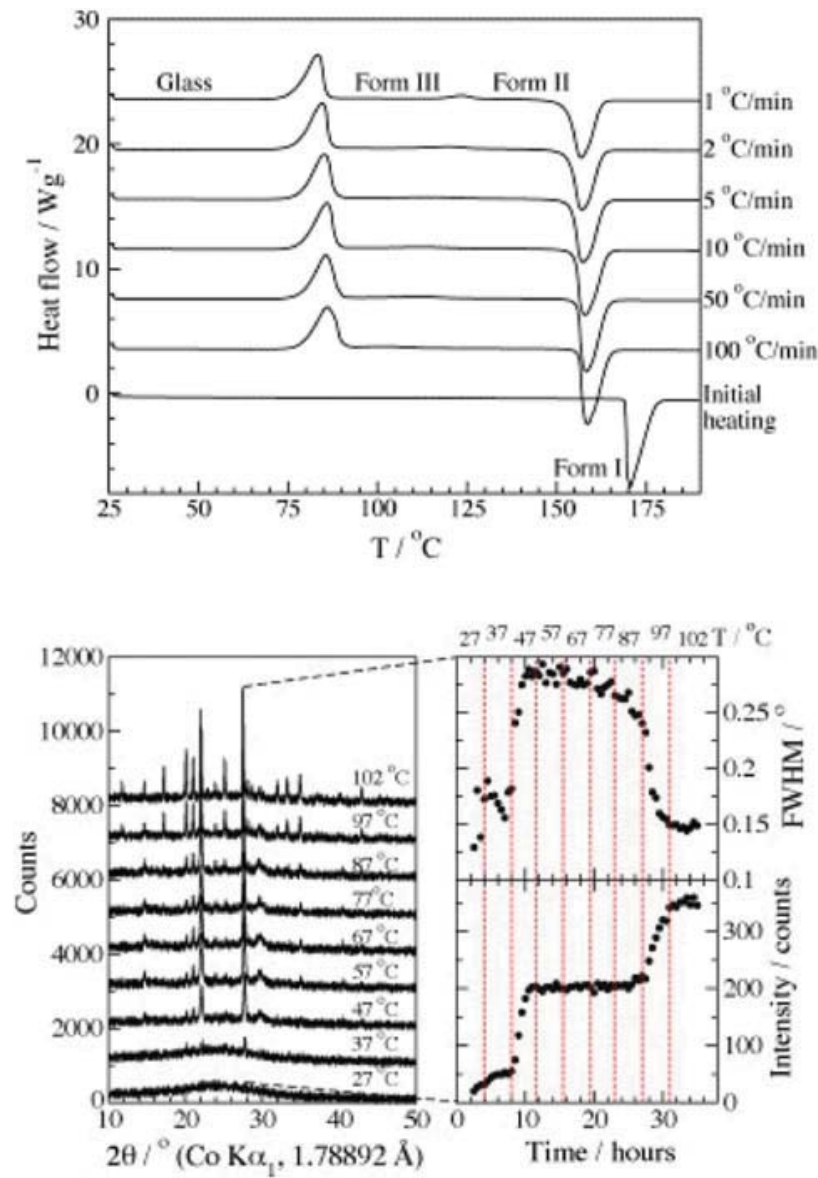

Fig. 32 DSC traces of the paracetamol (top) and temperature dependent PXDR (bottom). Reprinted from Publication. ${ }^{135}$ Copyright ${ }^{\circ} 2007$, with permission from Elsevier.

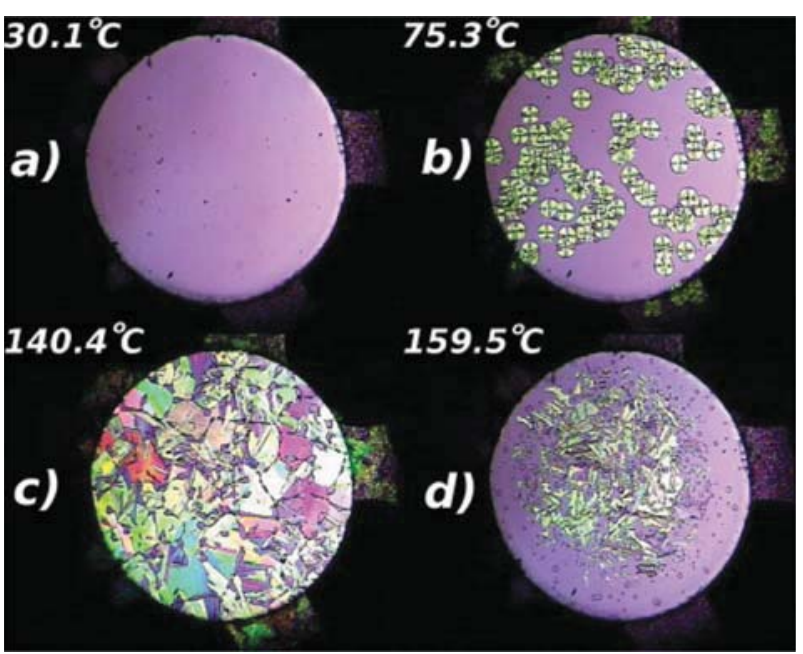

Fig. 33 Hot stage microscope view of the paracetamol as a function of temperature. (a) Glass form, (b) Form III, (c) From II and (d) melt. Reprinted from Publication. ${ }^{135}$ Copyright ${ }^{\circ} 2007$, with permission from Elsevier. Video film is available in the supplementary materials of. ${ }^{135}$

One of the problems encountered by the pharmaceutical industry with paracetamol is its compression into tablets. ${ }^{127}$ This problem of compressibility is due to the packing of the molecules in the crystal structure, especially due to the hydrogen bonding motifs in form I. In this monoclinic form, the paracetamol molecules are packed in waves, in contrast to the form II (Fig. 31). In form II, the molecules form flat hydrogen bonded sheets. While these sheets are easily compressible, form II is difficult to isolate. For the moment, a wet granulation step is used for the compression of the form I. The question arose thus if one can isolate the third polymorphic form and if it is compressible. ${ }^{128,129}$

An amorphous form of paracetamol can be obtained by heating of form I (commercially available form) to $190{ }^{\circ} \mathrm{C}$ and rapid cooling to $25{ }^{\circ} \mathrm{C}$ at a cooling rate of $100{ }^{\circ} \mathrm{C} \mathrm{min}^{-1}$. Depending on the publication, ${ }^{130-134}$ this form is called glass, glassy or amorphous form. Under DSC (Fig. 32 top) as well as the hot-stage microscope (Fig. 33), ${ }^{135}$ the crystallization from the glass to the form III at $c a .75{ }^{\circ} \mathrm{C}$ can be observed, followed by the transition to form II around $140{ }^{\circ} \mathrm{C}$ and finally the melt at $159{ }^{\circ} \mathrm{C}$. The form III is only isolated during heating of the

Table 6 Comparison of the two diphenyl ether polymorphs ${ }^{138}$

\begin{tabular}{lll} 
Form & I & II \\
\hline Space group & $P 2_{1} / n$ & $P 2_{1} / c$ \\
$\boldsymbol{a}(\AA)$ & $9.961(4)$ & $12.1515(10)$ \\
$\boldsymbol{b}(\AA)$ & $8.022(3)$ & $6.5064(5)$ \\
$\boldsymbol{c}(\AA)$ & $12.274(5)$ & $11.3677(9)$ \\
$\boldsymbol{\beta}\left({ }^{\circ}\right)$ & $106.993(6)$ & $111.574(3)$ \\
Volume $\left(\AA^{3}\right)$ & $938.0(2)$ & $835.79(12)$ \\
Temp. $(\mathbf{K})$ & $250(2)$ & $180(2)$ \\
$\boldsymbol{R}(\%)$ & 5.4 & 2.9 \\
$\boldsymbol{\tau}_{\mathbf{1}}\left(^{\circ}\right)$ & $88.39(7)$ & $87.60(4)$ \\
$\boldsymbol{\tau}_{\mathbf{2}}\left(^{\circ}\right)$ & $117.9(1)$ & $118.3(1)$ \\
Number of C-H $\cdots \pi(\AA)$ & 4 & 5 \\
CSD Code & RAFFIO01 & RAFFIO
\end{tabular}




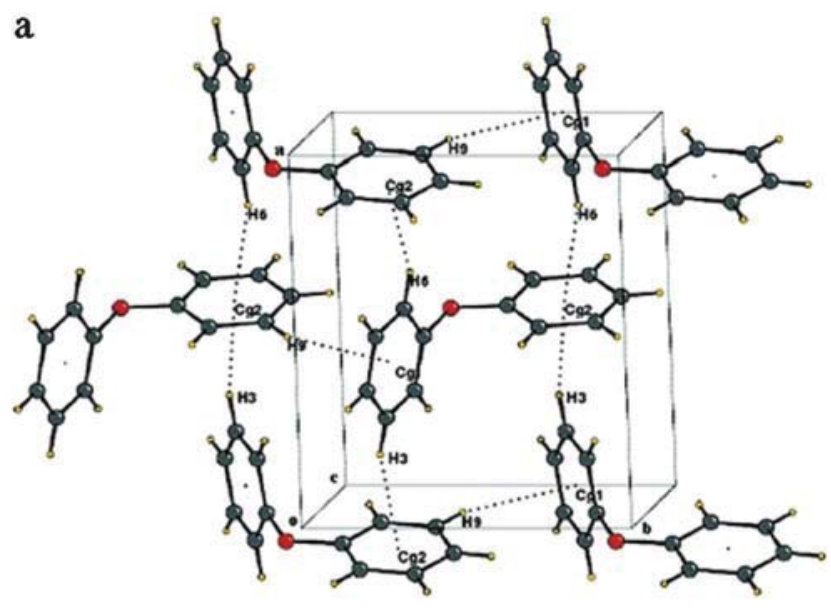

b

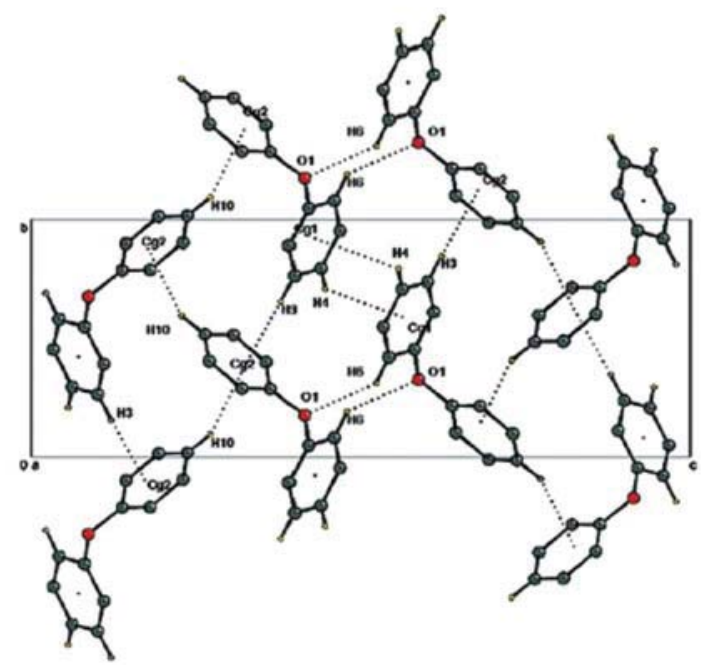

Fig. 34 (a) Packing of diphenyl ether molecules in form I. (b) Packing of diphenyl ether molecules in form II. Cg1 and $\mathrm{Cg} 2$ are the centroids of two phenyl rings C1 $\cdots$ C6 and C7 $\cdots$ C12. Reprinted from Publication ref. 138. Copyright ${ }^{\circ} 2004$, with permission from American Chemical Society.

glassy form from ambient to the melting temperature. With this technique, set up by Burley, solid state ${ }^{13} \mathrm{C}$ and ${ }^{15} \mathrm{~N}-\mathrm{NMR}$ spectra and powder diffractograms as a function of the temperature (Fig. 32 bottom) could also be measured. ${ }^{135}$

Based on this data, the three polymorphs can be classified from a thermodynamic point of view. The Form I is the most stable and it is monotropic with any of the two other forms.
Forms II and III are enantiotropes, as the transition from III to II takes place before the melting temperature. We also remark that the melting temperature is different for form I and form II with a higher temperature $\left(170{ }^{\circ} \mathrm{C}\right)$ for the stable form.

This example points out the fact that DSC is a powerful tool to determine stability range temperature and transitions from one phase to another. It shows also the fact that DSC can be used to define a method for isolating a highly metastable polymorph. The paracetamol history highlights also that temperature dependent powder X-ray diffraction can be used to determine the phase and also the structure. Indeed, the crystal structure of the paracetamol Form III was determined by resolution of the diffractogram. In order to measure the diffractogram of the form III, Perrin had sealed an air-free capillary with form I, and applied a double thermal cycle in an incubator. After an experiment of $80 \mathrm{~h}$, the obtained pattern is still the same, which shows that form III is stable enough in an air-free capillary. ${ }^{136}$

For more details on paracetamol see ref. 131, 135-137.

\section{C5. "Funny" cases}

High boiling point solvent crystallization. Crystallization in a capillary can be used for studying solvents in their solid forms. In 2004 Choudhury and Guru Row published two structures obtains by crystallization of diphenyl ether in capillary. ${ }^{138}$ Crystals were obtained by cooling a capillary full with solvent at different temperatures. The two structures obtained are packing polymorphs: Form I crystallizes in the monoclinic space group $P 2_{1} / n$, form II in the orthorhombic space group $P 2_{1} 2_{1} 2_{1}$ (Table 6). Indeed, the conformation of the two forms is extremely similar with angles between the two phenyl planes $88.39(7)^{\circ}$ and $87.60(4)^{\circ}$, respectively for form I and II. Differences in the packing modes of the two forms are due to intermolecular $\mathrm{C}-\mathrm{H} \cdots \pi$ interactions (Fig. 34). In form I molecules form a 3D network, in form II molecules form tetramers connected linked together by other $\mathrm{C}-\mathrm{H} \cdots \pi$ interactions. For more information, we advise you to refer to ref. 138.

Polymorphs with co-crystallizing agent. Research of new crystalline forms is extremely intensive with APIs, and new crystalline forms of fluconazole are also investigated (Table 7). This compound known since 1983 is an antifungal drug with at least twelve different crystalline forms: anhydrous, solvates, salts and co-crystals. During their investigations in co-crystals formation, Choudhury et al. have obtained four new anhydrous forms of fluconazole, two monoclinic (4 and 6) and two orthorhombic forms (5 and 7). ${ }^{139}$ These four polymorphs can

Table 7 Comparison of the fluconazole polymorphs ${ }^{139,140}$

\begin{tabular}{|c|c|c|c|c|c|c|}
\hline Form & $1^{140}$ & $4^{139}$ & $5^{139}$ & $6^{139}$ & $7^{139}$ & Monohydrate $^{140}$ \\
\hline Space group & $P \overline{1}$ & $P 2_{1} / n$ & $\mathrm{Pbca}$ & $C 2 / c$ & $\mathrm{Pbca}$ & $P \overline{1}$ \\
\hline$a(\AA)$ & $7.4992(1)$ & $6.6985(4)$ & $12.9282(9)$ & $27.4726(9)$ & $10.9186(9)$ & $5.6258(1)$ \\
\hline$b(\AA)$ & $7.7869(1)$ & $27.3858(19)$ & $6.0241(5)$ & $10.9196(4)$ & $22.3367(18)$ & $11.7373(2)$ \\
\hline$c(\AA)$ & $11.9817(2)$ & $15.2898(11)$ & $34.834(3)$ & $22.3424(12)$ & $22.3619(17)$ & $12.3063(3)$ \\
\hline$\alpha\left({ }^{\circ}\right)$ & $84.947(1)$ & 90 & 90 & 90 & 90 & $71.235(1)$ \\
\hline$\beta\left(^{\circ}\right)$ & $84.625(1)$ & $90.319(3)$ & 90 & $125.337(2)$ & 90 & $79.871(1)$ \\
\hline$\gamma\left({ }^{\circ}\right)$ & $75.894(1)$ & 90 & 90 & 90 & 90 & $84.383(1)$ \\
\hline Volume $(\AA)^{3}$ & $674.05(2)$ & $2804.8(3)$ & $2712.9(4)$ & $5467.6(4)$ & $5453.74(8)$ & $756.68(3)$ \\
\hline CSD Code & IVUQOF & IVUQOF & IVUQOF & IVUQOF & IVUQOF & IVUQIZ \\
\hline
\end{tabular}




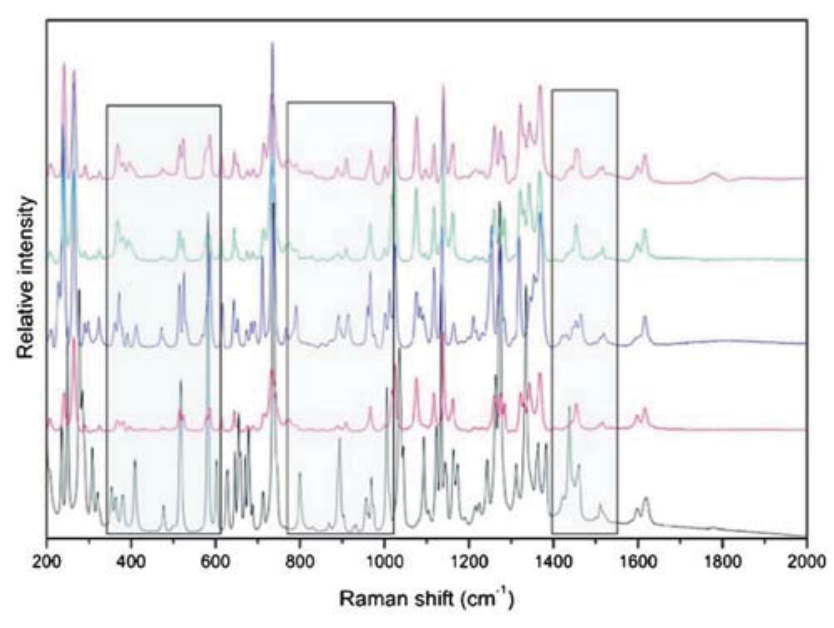

Fig. 35 Raman spectra of the polymorph 4 (black), polymorph 5 (red), polymorph 6 (blue), polymorph 7 (light green), and fluconazole monohydrate (pink). Reprinted from Publication ref. 139. Copyright ${ }^{\circ} 2012$, with permission from American Chemical Society.

be classified as conformational polymorphs due to the large difference of the molecular conformations. These new forms are only available via this route of crystallization, while seeding of saturated solutions of Fluconazole in the same solvent systems but without the respective co-crystallizing agent results in the formation of the anhydrous or the monohydrate form (Fig. 35). However, all forms can be reproduced with the same solvent systems and co-crystal former proportions. For more information refer to ref. 139.

The last part of this review will be focus on organo-metallic compounds, but before illustrate polymorphism with examples, it is important to define and delimit some new terms.

\section{Organo-metallic polymorphs}

\section{D1. Definitions}

Polymorphism for organometallic compounds is more difficult to define properly compared to purely organic compounds (see section C). As it is explained in the textbook Crystal Engineering, "a pair of coordination compounds can have the same chemical formula but different structures. [...] In these compounds, concepts such as "same chemical substance" or "same molecule" are not always clear."15 The definition of polymorphs is thus a big issue. For example, Bernstein, in his book "Polymorphism in Molecular Crystals", ${ }^{19}$ says: "The "safe" criterion for classification of a system as polymorphic would be if the crystal structures are different but lead to identical liquid and vapour states." This definition is too wide because, according to this definition, solvates, organo-metallic isomers and tautomers would be polymorphic even if they are pseudo-polymorphs or, worse, not even the same compound. Besides, compounds which decompose before the melting point will not be considered.

In contrast to the definition of Bernstein, Moulton \& Zaworotko explained that when a superstructure is different

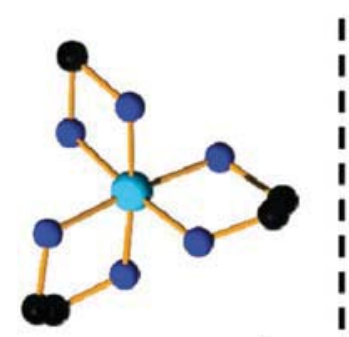

$\Lambda$

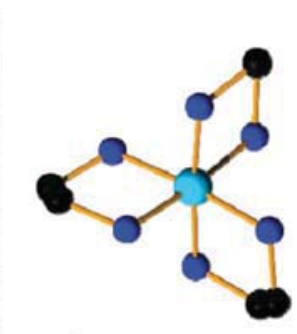

$\Delta$

Fig. $36 \Lambda$-Tris(ethylendiamine)cobalt(III) ${ }^{143}$ and

$\Delta$-tris(ethylendiamine)cobalt(III). ${ }^{144}$ Hydrogen and chlorine atoms are omitted for clarity.

due to the solvent or a guest molecule, polymorphism is an inappropriate term, which is in agreement with the definition of Gavezzotti: "Polymorphs are a set of crystals (a) with identical chemical composition; (b) made of molecules with same molecular connectivity, but allowing for different conformation by rotation about single bonds, (c) with distinctly different three-dimensional translationally periodic symmetry operations.". ${ }^{21,141}$ For organo-metallic polymorphs, Gavezzotti's definition of polymorphism ${ }^{21}$ will be considered as most suitable since this definition does not leave room for ambiguities but includes all compounds.

Not only solvates or host/guest complexes need to be looked at with care. Another prominent example are optical isomers concerning their chirality. The simplest optical isomers in organometallic compounds are metal ions coordinated with three bidentate ligands. Two enantiomers are available: $\Delta$ (delta) and $\Lambda$ (lambda) complexes. To differentiate them, the 3 -fold axis of the octahedron needs to point towards the reader. If the ligands then form a right-handed helix, this complex is defined as $\Delta$ and if the ligands form a left-handed helix, the complex is defined as $\Lambda$. The $\Delta$ or $\Lambda$ complexes are identical concerning the connectivity between metal ion and ligands. Here, only the relative positions of bidentate ligands are different as shown in Fig. 36 for tris(ethylendiamine)cobalt(III) (Table 8). ${ }^{142}$ The packing of both enantiomers is the same but the $\Delta$-enantiomer cannot be obtained by torsion, rotation or another degree of freedom from the $\Lambda$-enantiomer. To transform one enantiomer into the other, bonds need to be broken and rebound at another position (Fig. 37). Hence, optical isomers are not polymorphs

Table 8 X-ray data for the two isomers

\begin{tabular}{lll} 
Form & $\Lambda$ form $^{143}$ & $\Delta$ form $^{144}$ \\
\hline Space group & $P \overline{3} c_{1}$ & $P \overline{3} c_{1}$ \\
$\boldsymbol{a}(\AA)$ & 10.75 & 10.81 \\
$\boldsymbol{b}(\AA)$ & 10.75 & 10.81 \\
$\boldsymbol{c}(\AA)$ & 15.50 & 15.54 \\
$\boldsymbol{\alpha}\left({ }^{\circ}\right)$ & 90.00 & 90.00 \\
$\boldsymbol{\beta}\left({ }^{\circ}\right)$ & 90.00 & 90.00 \\
$\gamma\left({ }^{\circ}\right)$ & 120.00 & 120.00 \\
Volume $\left(\AA^{3}\right)$ & 1572.71 & 1550.36 \\
CSD code & IRIRAC & IRIRAC01
\end{tabular}




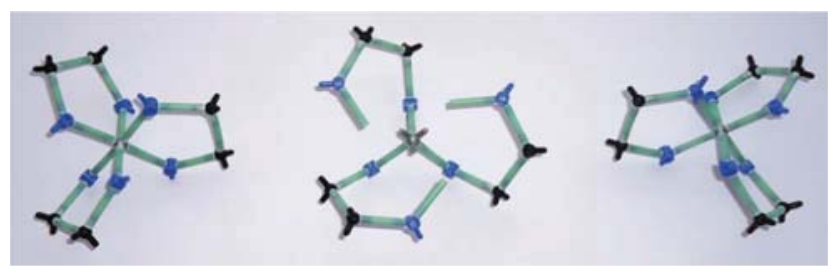

Fig. 37 Transformation from $\Lambda$ to $\Delta$ configuration with a molecular model kit.

according to the definition of Gavezzotti. So, a simple way to determine whether a compound is a polymorph of another compound is to find out if one or more bonds need to be broken to obtain the other compound.

\section{D2. Conformational and packing polymorphism}

On the basis of conformational and packing polymorphism, organo-metallic polymorphs can be distinguished in the same way as organic polymorphs, with one big difference: the organometallic bonds, especially the bond between an aromatic ring, e.g. a cyclopentadienyl moiety, and a metal ion by the center of the aromatic system (Scheme 5). This bond is defined to be a single bond. As for organic polymorphs, then two kinds of organometallic polymorphs can be distinguished for such compounds in a first step: conformational polymorphs and packing polymorphs.

Conformational polymorphism. For conformational polymorphs, two different types can be found. The first one is due to the different position of ligands relative to each other. Ferrocene, which has in total three polymorphs ${ }^{145}$ is a nice example for this kind of polymorphism since only the relative position of the cyclopentadienyl anions is different (Fig. 38 and Table 9). This difference can be very small (less than $10^{\circ}$ ) but results in a very different packing as shown in Fig. 38, starting from the eclipsed conformation (I $\rightarrow$ II). Another $170^{\circ}$ turn results in the staggered conformation (II $\rightarrow$ III) and in a packing which only differs from form II in the space between the ferrocene units (Fig. 38, Table 9). ${ }^{146}$ The different polymorphs of ferrocene are due to phase transitions. The eclipsed ferrocene transforms into the near to eclipsed ferrocene at $164 \mathrm{~K}$, and the latter adopts the staggered form at $242 \mathrm{~K}$.

Other types of conformational polymorphism are due to a difference in the conformation of the ligand itself. Especially flexible ligands can have different conformations according to internal rotations, torsions, etc. The conformation of the
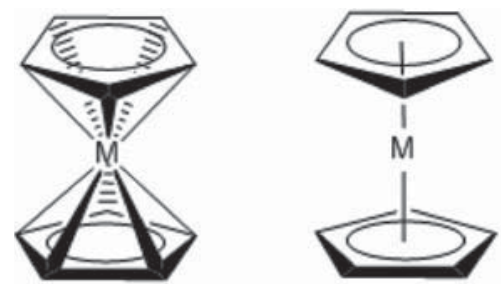

Scheme 5 Two different ways to draw a bond between a metal ion and an aromatic ring system.

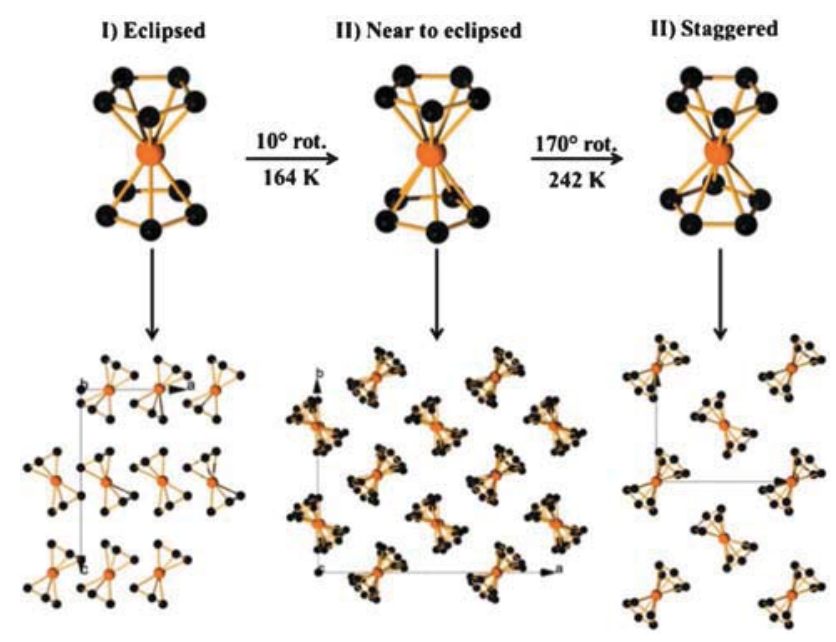

Fig. 38 Change in the relative position of the cyclopentadienyl anions and the resulting packing. Hydrogen atoms are omitted for clarity.

Table 9 X-ray data for the three polymorphs of ferrocene

\begin{tabular}{llll}
\hline Form & I & II & III \\
\hline Space group & Pnma & $F \overline{1}$ & $P 2_{1} / a$ \\
$\boldsymbol{a}(\AA)$ & 6.99 & 20.98 & 10.56 \\
$\boldsymbol{b}(\AA)$ & 15.04 & 7.60 \\
$\boldsymbol{c}(\AA)$ & 9.00 & 11.45 & 5.95 \\
$\boldsymbol{\alpha}\left({ }^{\circ}\right)$ & 12.20 & 89.52 & 90.00 \\
$\boldsymbol{\beta}\left(^{\circ}\right)$ & 90.00 & 120 & 121.02 \\
$\gamma\left({ }^{\circ}\right)$ & 90.00 & 90.58 & 90.00 \\
Volume $\left(\AA^{3}\right)$ & 90.00 & 3127.18 & 409.25 \\
CSD code & 766.50 & FEROCE16 & FEROCE01 \\
& FEROCE24 & &
\end{tabular}

ligand does neither influence the connectivity between the metal ion and the ligand nor the relative position to the metal ion. One such example is the chloro[tris(2cyanoethyl)phosphine]gold(I) (Table 10). ${ }^{147}$ An overlay of the two existing polymorphs easily shows the conformational changes of the ligands (Fig. 39).

Packing polymorphism. Packing polymorphism can be defined as polymorphs consisting of exactly the same complex (same angles, torsions,...) but which are packed in different ways. In a carboxylated derivative of ferrocene, which exists in three different packings, this polymorphism becomes evident (Fig. 40, Table 11). ${ }^{148}$ The commercial powder of this compound contains the two first polymorphs. The first one is favored kinetically but the second form is thermodynami-

Table 10 X-ray data for the two polymorphs

\begin{tabular}{lll}
\hline Form & I & II \\
\hline Space group & $P 2_{1} / c$ & $P 22_{1} / c$ \\
$\boldsymbol{a}(\AA)$ & 8.56 & 11.76 \\
$\boldsymbol{b}(\AA)$ & 7.9 & 7.99 \\
$\boldsymbol{c}(\AA)$ & 19.03 & 13.42 \\
$\boldsymbol{\beta}\left({ }^{\circ}\right)$ & 99.82 & 95.75 \\
Volume $\left(\AA^{3}\right)$ & 1278.67 & 1254.05 \\
CSD code & LESNOM01 & LESNOM
\end{tabular}




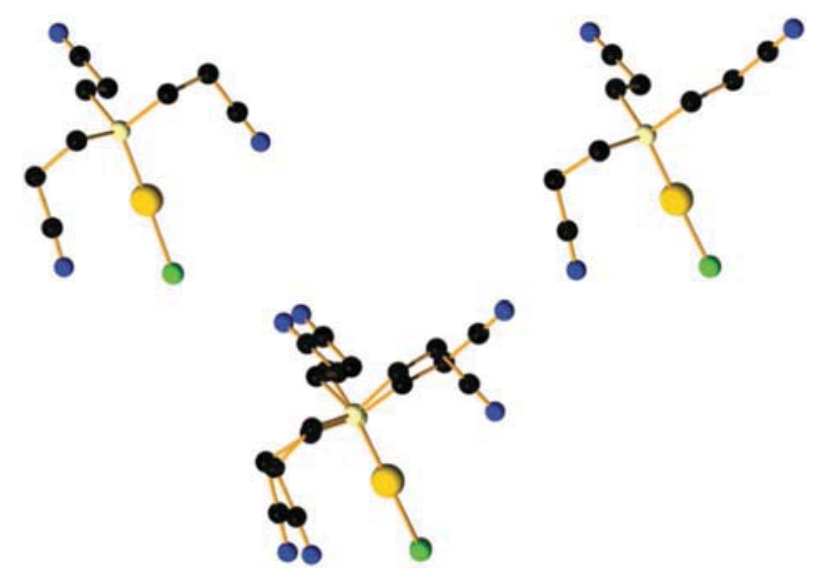

Fig. 39 (top) Two polymorphs of chloro[tris(2-cyanoethyl)phosphine]gold(।) with different ligand conformation; (bottom) overlay of the two polymorphs. Hydrogen atoms are omitted for clarity. Adapted from ref. 147. Copyrights ${ }^{(}$ 1994, IUCr.

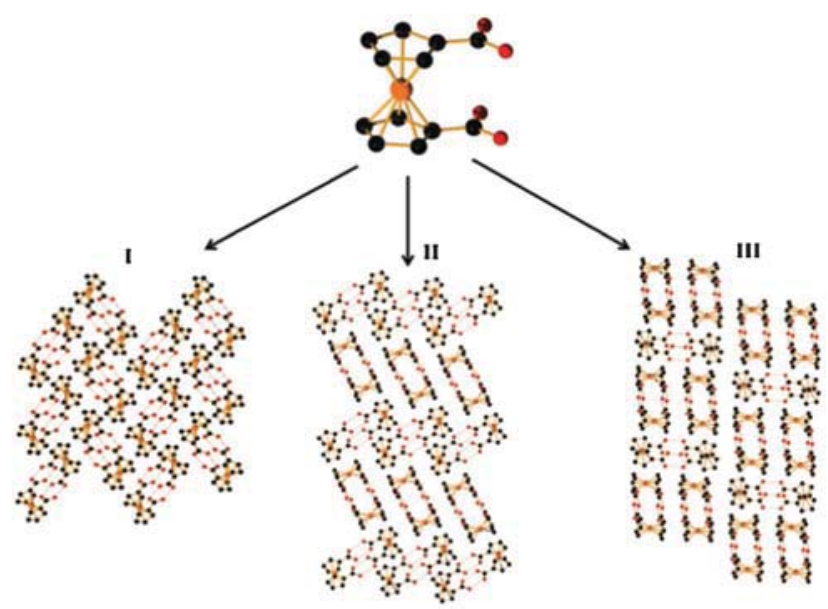

Fig. 40 The single complexes of derivative of ferrocene cannot be distinguished but the packing is completely different. Hydrogen atoms are omitted for clarity. Adapted with permission from ref. 149. Copyright $\odot 2004$ American Chemical Society.

cally more stable. The second form can be "transformed" into the first polymorph by recrystallization from acetic acid or by adding and removing ammonia. The third form is only obtained by crystallization at low temperature. ${ }^{149}$

Table $11 \mathrm{X}$-ray data for the three polymorphs

\begin{tabular}{llll}
\hline Form & I & II & III \\
\hline Space group & $P 2_{1} / c$ & $P \overline{1}$ & $P \overline{1}$ \\
$\boldsymbol{a}(\stackrel{\AA}{\mathbf{A}})$ & 8.40 & 7.42 & 7.92 \\
$\boldsymbol{b}(\AA)$ & 8.91 & 7.81 & 14.38 \\
$\boldsymbol{c}(\stackrel{\AA}{\AA})$ & 14.19 & 18.12 & 14.61 \\
$\boldsymbol{\alpha}\left({ }^{\circ}\right)$ & 90.00 & 98.79 & 110.68 \\
$\boldsymbol{\beta}\left(^{\circ}\right)$ & 90.41 & 91.07 & 90.07 \\
$\gamma\left(\left(^{\circ}\right)\right.$ & 90.00 & 97.21 & 94.78 \\
Volume $\left(\AA^{\circ}\right)$ & 1062.54 & 1029.06 & 1549.2 \\
CSD code & FEROCA & FEROCA12 & FEROCA13
\end{tabular}

\section{D3. Polymorphs of coordination polymers}

Coordination polymers are organometallic compounds that can go to "infinite" in one, two or three dimensions. ${ }^{150}$ According to this definition, they can be seen as supramolecular compounds, which form a "family" with all the metalorganic frameworks (MOFs), also referred to as metal-organic coordination networks (MOCNs). The assembly of defined organic molecules and metal ions as building blocks for coordination polymers can often take place in different ways and can thus produce supramolecular isomers.

In this kind of isomers, it is possible to find polymorphs. In fact, all polymorphs of coordination polymers are supramolecular isomers but the reverse is not always true. ${ }^{141}$ For the definition of "polymorphism", it is important to make the difference between a polymorph of coordination polymer and a supramolecular isomer that is not polymorphic. With the definition of Bernstein, ${ }^{19}$ all the MOFs and MOCNs which decompose before to melt made from the same "building blocks" cannot be polymorphs. According to the more restrictive definition of Gavezzotti, ${ }^{21}$ all these compounds can be investigated for polymorphism. An illustrating example for the importance of the chosen definition was published in 2005 by our research group. ${ }^{151}$ The title of this publication "Concomitant crystallization of two polymorphs - a ring and a helix: Concentration effect on supramolecular polymorphism" already shows the problem. It is impossible to obtain a helix from a ring without breaking any bond. At the time, we based our use of the term "polymorphism" on the same chemical formula and the same connectivity between the atoms, and in this definition, we used the term correctly. Yet, the dimensionality of a ring is different (0D) from the one of a helix (1D). Hence, they are rather supramolecular isomers and not polymorphic coordination polymers following the definition of Gavezzotti.

Coordination polymer polymorphs can be differentiated in the same way as other organo-metallic polymorphs into conformational and packing polymorphs (see section D2). In a 1D coordination polymorph, a lot of shapes can be adopted by one ligand and one linearly coordinated metal ion as shown in Scheme 6. However, in this kind of polymorphism, the quantity of solvent molecules and the connectivity (or not) of counter-ions has to be verified carefully, especially the often omitted molecules for clarity (often solvent molecules), to clearly decide if it is true polymorphism or not.

A nice example of conformational polymorphs is given by Lee \& Wang with the [1,4-bis(3-pyridyl)-2,3-diazo-1,3-butadiene]-dichloro-Zn(II) polymers (Fig. 41 , Table 12). ${ }^{152}$

Another example was previously realized in our group with silver ions and the ethanediyl bis(isonicotinate) ligand (Fig. 42, Table 13). ${ }^{153}$ This example shows perfectly the shapes I and II of Scheme 6 .

However, for other cases, the difference can be less visible as explained previously. For example, two helices of trifluoromethane sulfonate [2,3-dipyridyl keton]silver(I) are polymorphs with the difference being the density of the packing as shown in Fig. 43 and Table $14 .{ }^{154}$

For coordination polymer polymorphism, the second type of polymorphism based on the different packing of identical 


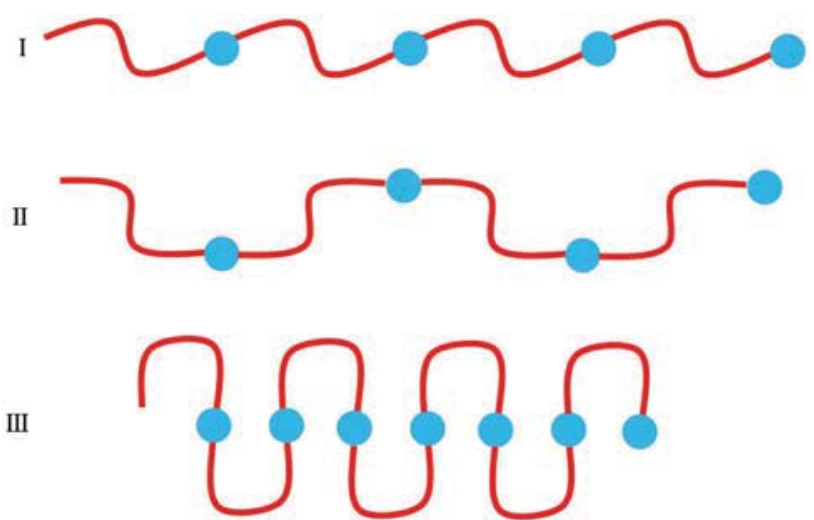

Scheme 6 Schematisation of 1D coordination polymers made of one flexible ligand with a metal ion of coordination number $\mathrm{CN}=2$. In I and II the ligand does not change its conformation. In III the ligand changes its conformation. ${ }^{151}$ Copyright $\odot 2005$ WILEY-VCH Verlag GmbH \& Co. KGaA, Weinheim.
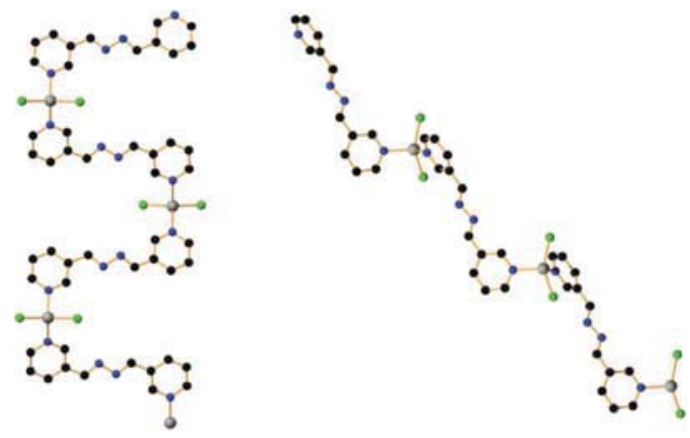

Fig. 41 Changes in the relative position of 1,4-bis(3-pyridyl)-2,3-diazo-1,3butadiene. A slight torsion of the ligand gives yield to two polymorphs of a coordination polymer. Hydrogen atoms are omitted for clarity. ${ }^{152}$ Copyright ${ }^{\circ}$ 2009 WILEY-VCH Verlag GmbH \& Co. KGaA, Weinheim.

substructures is rare. A nice example is the reaction of zinc bromide with 2,5-dimethylpyrazine (Fig. 44, Table 15), which can perfectly illustrate this kind of polymorphism. Both polymorphs are obtained in the same way but the first form is more stable. ${ }^{155}$

Table 12 X-ray data for the two polymorphs

\begin{tabular}{lll}
\hline Form & I & II \\
\hline Space group & $P 2_{1} / n$ & $P n a 2_{1}$ \\
$\boldsymbol{a}(\AA)$ & 9.18 & 7.97 \\
$\boldsymbol{b}(\AA)$ & 14.60 & 21.47 \\
$\boldsymbol{c}(\AA)$ & 10.37 & 8.25 \\
$\boldsymbol{\alpha}\left({ }^{\circ}\right)$ & 90.00 & 90.00 \\
$\boldsymbol{\beta}\left(^{\circ}\right)$ & 98.23 & 90.00 \\
$\gamma\left({ }^{\circ}\right)$ & 90.00 & 90.00 \\
Volume $\left(\AA^{3}\right)$ & 1374.14 & 1410.81 \\
CSD code & DEMVAT & DEMVAT01
\end{tabular}

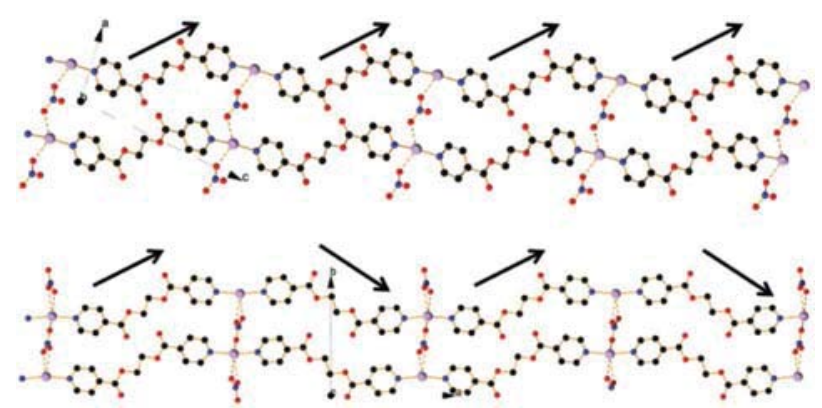

Fig. 42 No changes in the ligand conformation but only in relative position of the ligand. Hydrogen atoms are omitted for clarity. Reproduced from ref. 153.

Table 13 X-ray data for the two polymorphs

\begin{tabular}{lll}
\hline Form & I & II \\
\hline Space group & $P \overline{1}$ & $P 2_{1} / n$ \\
$\boldsymbol{a}(\AA)$ & 6.16 & 11.67 \\
$\boldsymbol{b}(\AA)$ & 8.90 & 11.07 \\
$\boldsymbol{c}(\stackrel{\AA}{\AA})$ & 14.44 & 12.18 \\
$\boldsymbol{\alpha}\left({ }^{\circ}\right)$ & 93.15 & 90.00 \\
$\boldsymbol{\beta}\left({ }^{\circ}\right)$ & 99.90 & 99.02 \\
$\gamma\left({ }^{\circ}\right)$ & 91.43 & 90.00 \\
Volume $\left(\AA^{3}\right)$ & 777.62 & 1555.16
\end{tabular}

\section{D4. Solvates as precursors}

As explained before, the first test for polymorphism is the investigation of the chemical bonding, the solvent molecules and the counter-ions. Even if solvates are not polymorphs with desolvated compounds, they can act as precursors for polymorphs. In some cases, a solvate can be heated to remove

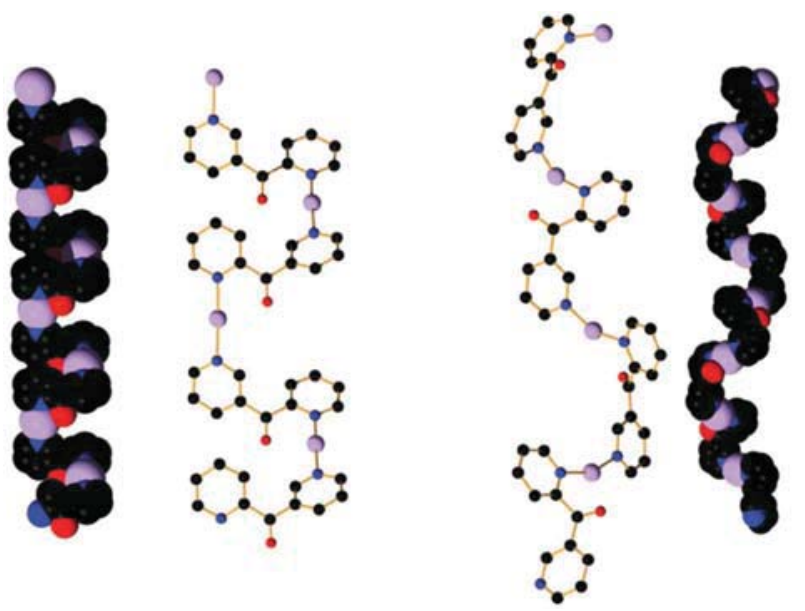

Fig. 43 Two polymorphs of trifluoromethane sulfonate [2,3-dipyridyl ketone]silver(I) represented in two styles: spacefilling model on the extreme left and right, and ball and stick representation in the middle; Hydrogen atoms and trifluoromethane sulfonate anions are omitted for clarity. Reproduced from ref. 154. 
Table 14 X-ray data for the two polymorphs

\begin{tabular}{lll}
\hline Form & I & II \\
\hline Space group & $P 2_{1} / c$ & $P 4_{1} 2_{1} 2$ \\
$\boldsymbol{a}(\AA)$ & 9.54 & 10.24 \\
$\boldsymbol{b}(\AA)$ & 12.44 & 10.24 \\
$\boldsymbol{c}(\AA)$ & 13.32 & 28.11 \\
$\boldsymbol{\alpha}\left({ }^{\circ}\right)$ & 90.00 & 90.00 \\
$\boldsymbol{\beta}\left({ }^{\circ}\right)$ & 105.17 & 90.00 \\
$\gamma\left({ }^{\circ}\right)$ & 90.00 & 90.00 \\
Volume $\left(\AA^{3}\right)$ & 1526.68 & 2944.43 \\
CCDC code & 271230 & 271231
\end{tabular}

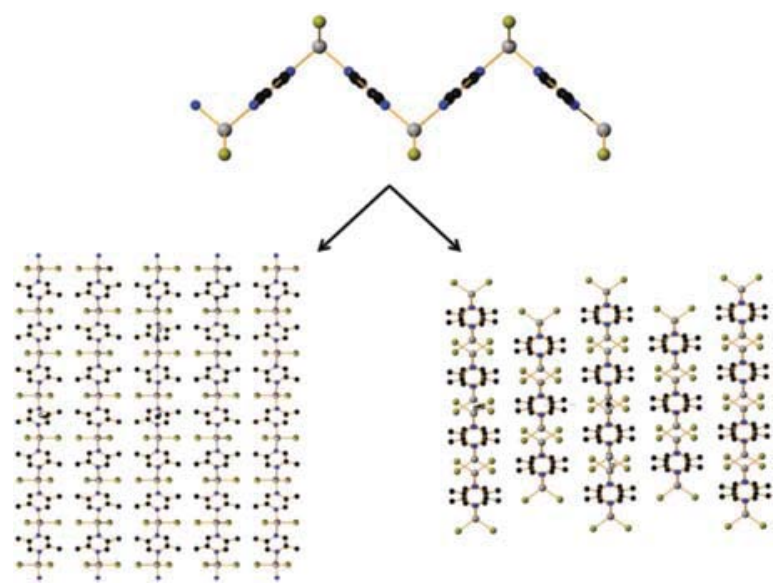

Fig. 44 Two polymorphs of $\left[\mathrm{ZnBr}_{2}\right.$ (2,5-dimethylpyrazine)]. Hydrogen atoms are omitted for clarity. Adapted from ref. 155. Copyright (๑) 2009 WILEY-VCH Verlag $\mathrm{GmbH} \&$ Co. KGaA, Weinheim.

Table 15 X-ray data for the two polymorphs

\begin{tabular}{lll}
\hline Form & I & II \\
\hline Space group & Pnma & $C 2 / c$ \\
$\boldsymbol{a}(\AA)$ & 6.27 & 16.15 \\
$\boldsymbol{b}(\AA)$ & 10.32 & 6.49 \\
$\boldsymbol{c}(\AA$ & 14.38 & 9.88 \\
$\boldsymbol{\beta}\left({ }^{\circ}\right)$ & 90.00 & 115.10 \\
Volume $\left(\AA^{3}\right)$ & 930.42 & 937.29 \\
CSD code & DOPYIR & DOPYIR01
\end{tabular}

solvent molecules in order to yield a polymorph of an anhydrous compound (Table 16). ${ }^{156}$ During heating, the solvent molecules "leave" the compound, while the newly formed polymorph maintains the conformation and relative position of the ligands around the metal ion of the solvate (Fig. 45).

\section{D5. Conclusions}

Examples for all types of organometallic polymorphs were discussed in an as simple way as possible, which, however,
Table 16 X-ray data for the solvate and the two polymorphs

\begin{tabular}{llll}
\hline Form & Solvate & I & II \\
\hline Space group & Cmcm & $P 2_{1} / m$ & Ibam \\
$\boldsymbol{a}(\AA)$ & 16.96 & 9.06 & 7.92 \\
$\boldsymbol{b}(\AA)$ & 6.24 & 7.40 & 11.49 \\
$\boldsymbol{c}(\AA)$ & 7.28 & 5.60 & 7.78 \\
$\boldsymbol{\beta}\left({ }^{\circ}\right)$ & 90.00 & 99.48 & 90.00 \\
Volume $\left(\AA^{3}\right)$ & 770.27 & 369.98 & 707.60 \\
CSD code & - & - & KELCIN \\
& & & \\
\hline
\end{tabular}

sometimes is not easy due to the different definitions. Thus, a solvate can be a polymorph of another solvate if, first of all, the number of solvent molecules is the same and, secondly, the connectivity of solvent to the complex is identical. In the same way, a salt can form polymorphs as well. The determination of polymorphism for a salt, a solvate, etc. can be determined in the same way as for the herein discussed organometallic compounds.

\section{E. Conclusions}

Polymorphism is a very important phenomenon not only in basic research, but certainly in pharmaceutical industry and materials science. Polymorphs possess different properties, for instance the solubility or the mechanical resistance can differ dramatically from one polymorph to the other - properties which can be crucial for their application. Hence, it is important to be able to control the formation of polymorphs and to understand their formation. We here gave some insights into the basic knowledge of polymorph formation and their identification and characterization in order to give an overview on the current state of the art. Depending on the compound classes, examples of polymorphs were given. Particularly for organic compounds, there seems to be a large number of polymorphs possible if for example many hydrogen bonds can be formed between the individual molecules. Thus, for many compounds and depending on the external conditions, there may just as well be still a number of polymorphs to be discovered - depending on how much time and energy we spend searching for them. One might think here of research

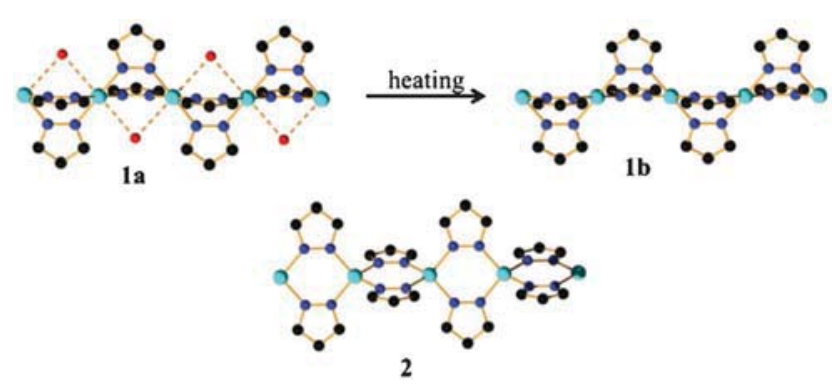

Fig. $\mathbf{4 5}$ The solvate $\mathbf{1 a}$ forms solvent-free $\mathbf{1} \mathbf{b}$ by gentle heating, which is a polymorph of $\mathbf{2}$. Hydrogen atoms omitted for clarity. Adapted with permission from ref. 156. Copyright (C) 2005) American Chemical Society. 


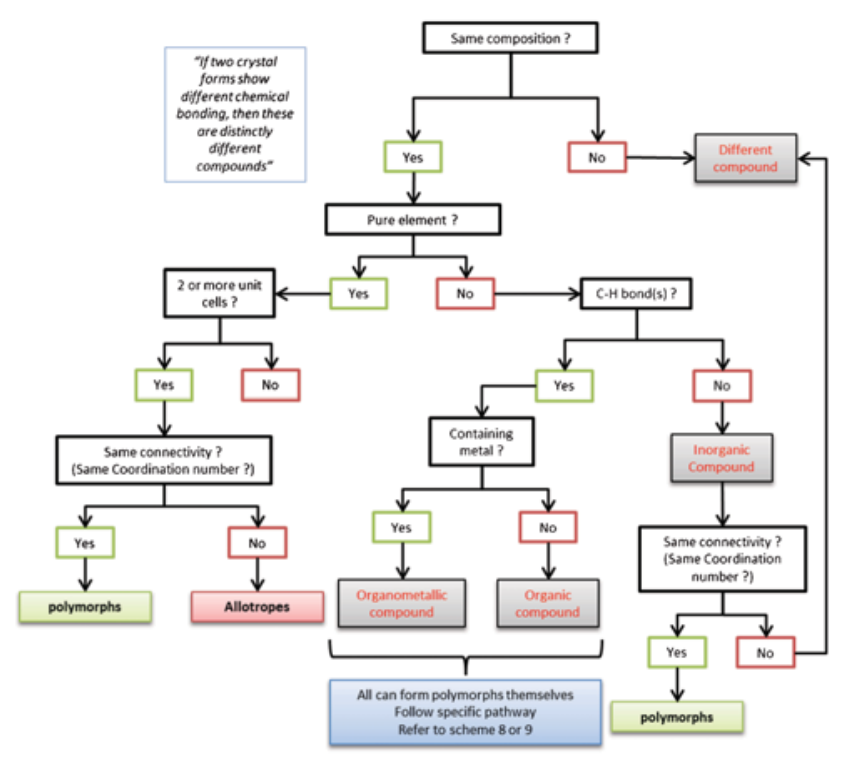

Scheme $\mathbf{7}$ Chart for the selection of the nomenclature/classification.

being done under extremely high pressure or, on the contrary, in space.

In order to give interested readers a tool in hand to test their compounds for polymorphism, we established a series of flow sheets to follow, depending on the class of compounds, hoping that they are useful for many scientists who are not so well acquainted with polymorphism. The Schemes 7-9 resume thus the identification steps for polymorphs. It should also help to use the term polymorph correctly in order to reduce the

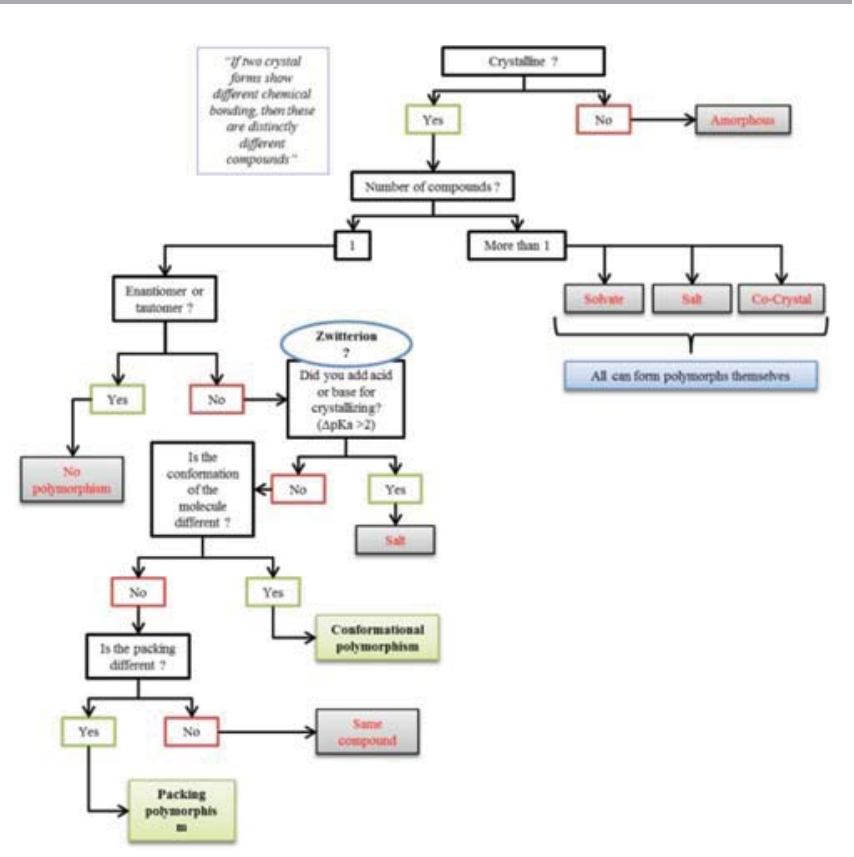

Scheme 8 Pathway for polymorphism determination, organic compound version.

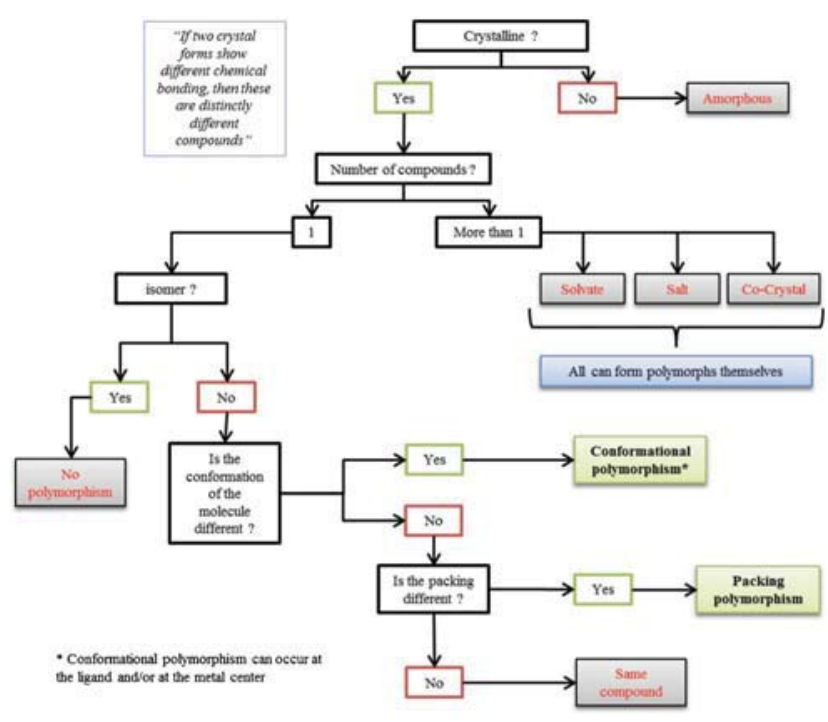

Scheme 9 Pathway for polymorphism determination, organometallic compound version.

number of publications in which this term is not used in a correct way.

\section{References}

1 O. G. Uzoh, A. J. Cruz-Cabeza and S. L. Price, Cryst. Growth Des., 2012, 12(8), 4230.

2 J. Spencer, H. Patel, J. J. Deadman, R. A. Palmer, L. Male, S. J. Coles, O. G. Uzoh and S. L. Price, CrystEngComm, 2012, 14(20), 6441.

3 J.-B. Arlin, L. S. Price, S. L. Price and A. J. Florence, Chem. Commun., 2011, 47(25), 7074.

4 K. Sanderson, Nature, 2007, 450(7171), 771.

5 G. M. Day, T. G. Cooper, A. J. Cruz-Cabeza, K. E. Hejczyk, H. L. Ammon, S. X. M. Boerrigter, J. S. Tan, R. G. Della Valle, E. Venuti, J. Jose, S. R. Gadre, G. R. Desiraju, T. S. Thakur, B. P. van Eijck, J. C. Facelli, V. E. Bazterra, M. B. Ferraro, D. W. M. Hofmann, M. A. Neumann, F. J. J. Leusen, J. Kendrick, S. L. Price, A. J. Misquitta, P. G. Karamertzanis, G. W. A. Welch, H. A. Scheraga, Y. A. Arnautova, M. U. Schmidt, J. van de Streek, A. K. Wolf and B. Schweizer, Acta Crystallogr., Sect. B: Struct. Sci., 2009, 65(2), 107.

6 J. Dresp, E. Schmid and M. Bauchinger, Mutat. Res., Fundam. Mol. Mech. Mutagen., 1978, 56(3), 341.

7 A. R. Oganov and C. W. Glass, J. Chem. Phys., 2006, 124(24), 244704.

8 J. P. M. Lommerse, W. D. S. Motherwell, H. L. Ammon, J. D. Dunitz, A. Gavezzotti, D. W. M. Hofmann, F. J. J. Leusen, W. T. M. Mooij, S. L. Price, B. Schweizer, M. U. Schmidt, B. P. van Eijck, P. Verwer and D. E. Williams, Acta Crystallogr., Sect. B: Struct. Sci., 2000, 56(4), 697.

9 W. D. S. Motherwell, H. L. Ammon, J. D. Dunitz, A. Dzyabchenko, P. Erk, A. Gavezzotti, D. W. M. Hofmann, F. J. J. Leusen, J. P. M. Lommerse, W. T. M. Mooij, S. L. Price, H. Scheraga, B. Schweizer, M. 
U. Schmidt, B. P. van Eijck, P. Verwer and D. E. Williams, Acta Crystallogr., Sect. B: Struct. Sci., 2002, 58(4), 647.

10 G. M. Day, W. D. S. Motherwell, H. L. Ammon, S. X. M. Boerrigter, R. G. Della Valle, E. Venuti, A. Dzyabchenko, J. D. Dunitz, B. Schweizer, B. P. van Eijck, P. Erk, J. C. Facelli, V. E. Bazterra, M. B. Ferraro, D. W. M. Hofmann, F. J. J. Leusen, C. Liang, C. C. Pantelides, P. G. Karamertzanis, S. L. Price, T. C. Lewis, H. Nowell, A. Torrisi, H. A. Scheraga, Y. A. Arnautova, M. U. Schmidt and P. Verwer, Acta Crystallogr., Sect. B: Struct. Sci., 2005, 61(5), 511.

11 D. A. Bardwell, C. S. Adjiman, Y. A. Arnautova, E. Bartashevich, S. X. M. Boerrigter, D. E. Braun, A. J. Cruz-Cabeza, G. M. Day, R. G. Della Valle, G. R. Desiraju, B. P. van Eijck, J. C. Facelli, M. B. Ferraro, D. Grillo, M. Habgood, D. W. M. Hofmann, F. Hofmann, K. V. J. Jose, P. G. Karamertzanis, A. V. Kazantsev, J. Kendrick, L. N. Kuleshova, F. J. J. Leusen, A. V. Maleev, A. J. Misquitta, S. Mohamed, R. J. Needs, M. A. Neumann, D. Nikylov, A. M. Orendt, R. Pal, C. C. Pantelides, C. J. Pickard, L. S. Price, S. L. Price, H. A. Scheraga, J. van de Streek, T. S. Thakur, S. Tiwari, E. Venuti and I. K. Zhitkov, Acta Crystallogr., Sect. B: Struct. Sci., 2011, 67(6), 535.

12 Thomson Reuters, Web of science.

13 D. Braga, F. Grepioni, L. Maini and M. Polito, in Molecular Networks, ed. M. W. Hosseini, Springer Berlin Heidelberg, Berlin, Heidelberg, 2009, p. 25.

14 Wöhler and Liebig, Ann. Pharm., 1832, 3(3), 249.

15 G. R. Desiraju, J. J. Vittal and A. Ramanan, Crystal engineering: A textbook, World Scientific, New Jersey, 2011.

$16 \mathrm{~W}$. McCrone, Physics and chemistry of the organic solid state, Chapter 8, pp. 725-767, vol. 2, Polymorphism, Interscience, New York, 1965.

17 S. Rosenstein and P. P. Lamy, Amer. J. Hosp. Pharm., 1969, 26(10), 598.

18 A. Burger, in Top. Pharm. Sci., Proc. Int. Congr. Pharm. Sci. F.I.P. $43 r$, Elsevier, 1983, p. 347.

19 J. M. Bernstein, Polymorphism in molecular crystals, Oxford University Press, Oxford, 2002.

20 B. D. Sharma, J. Chem. Educ., 1987, 64(5), 404.

21 A. Gavezzotti, J. Pharm. Sci., 2007, 96(9), 2232.

22 R. Purohit and P. Venugopalan, Resonance, 2009, 14(9), 882.

23 M. Nič, J. Jirát, B. Košata, A. Jenkins and A. McNaught, IUPAC Compendium of Chemical Terminology, IUPAC, Research Triagle Park, NC, 2009.

24 S. Aitipamula, R. Banerjee, A. K. Bansal, K. Biradha, M. L. Cheney, A. R. Choudhury, G. R. Desiraju, A. G. Dikundwar, R. Dubey, N. Duggirala, P. P. Ghogale, S. Ghosh, P. K. Goswami, N. R. Goud, R. R. K. R. Jetti, P. Karpinski, P. Kaushik, D. Kumar, V. Kumar, B. Moulton, A. Mukherjee, G. Mukherjee, A. S. Myerson, V. Puri, A. Ramanan, T. Rajamannar, C. M. Reddy, N. Rodriguez-Hornedo, R. D. Rogers, T. N. G. Row, P. Sanphui, N. Shan, G. Shete, A. Singh, C. C. Sun, J. A. Swift, R. Thaimattam, T. S. Thakur, R. Kumar Thaper, S. P. Thomas, S. Tothadi, V. R. Vangala, N. Variankaval, P. Vishweshwar, D. R. Weyna and M. J. Zaworotko, Cryst. Growth Des., 2012, 12(5), 2147.
25 A. M. Campeta, B. P. Chekal, Y. A. Abramov, P. A. Meenan, M. J. Henson, B. Shi, R. A. Singer and K. R. Horspool, J. Pharm. Sci., 2010, n/a.

26 M. Akkurt, S. Öztürk, S. Servi, A. Cansız, M. Şekerci and C. Kazak, Acta Crystallogr.,Sect. E: Struct. Rep. Online, 2004, 60(9), 01507.

27 F. Jian, Z. Bai, H. Xiao and K. Li, Acta Crystallogr., Sect. E: Struct. Rep. Online, 2005, 61(3), o557.

28 I. R. Hanson, D. L. Hughes and M. R. Truter, J. Chem. Soc., Perkin Trans. 2, 1976(8), 972.

29 A. Crochet, E. Kottelat, A. Fleury, M. Neuburger and K. M. Fromm, Z. Anorg. Allg. Chem., 2011, 637(6), 672.

30 M. P. Thornberry, C. Slebodnick, P. A. Deck and F. R. Fronczek, Organometallics, 2000, 19(25), 5352.

31 J. Bernstein, R. J. Davey and J.-O. Henck, Angew. Chem., Int. Ed., 1999, 38(23), 3440.

32 P. Munshi, K. N. Venugopala, B. S. Jayashree and T. N. Guru Row, Cryst. Growth Des., 2004, 4(6), 1105.

33 C. B. Aakeröy and D. J. Salmon, CrystEngComm, 2005, 7(72), 439.

34 D. O. Calligaro, J. Fairhurst, T. M. Hotten, N. A. Moore and D. E. Tupper, Bioorg. Med. Chem. Lett., 1997, 7(1), 25.

35 L. Yu, G. A. Stephenson, C. A. Mitchell, C. A. Bunnell, S. V. Snorek, J. J. Bowyer, T. B. Borchardt, J. G. Stowell and S. R. Byrn, J. Am. Chem. Soc., 2000, 122(4), 585.

36 L. Yu, Acc. Chem. Res., 2010, 43(9), 1257.

37 L. A. Al-razzak, K. C. Marsh and R. A. Pyter, Pharmaceutical composition for HIV protease inhibitor [ritonavir] with improved oral bioavailability, WO 9509614A, filed 1994, published 1995.

38 J. Bauer, S. Spanton, R. Henry, J. Quick, W. Dziki, W. Porter and J. Morris, Pharm. Res., 2001, 18(6), 859.

39 S. L. Morissette, S. Soukasene, D. Levinson, M. J. Cima and O. Almarsson, Proc. Natl. Acad. Sci. U. S. A., 2003, 100(5), 2180.

40 S. R. Chemburkar, J. Bauer, K. Deming, H. Spiwek, K. Patel, J. Morris, R. Henry, S. Spanton, W. Dziki, W. Porter, J. Quick, P. Bauer, J. Donaubauer, B. A. Narayanan, M. Soldani, D. Riley and K. McFarland, Org. Process Res. Dev., 2000, 4(5), 413.

41 D. A. Young, Phase diagrams of the elements, Univ. California, 1975.

42 Michael Ströck, Eight Allotropes of Carbon, used under a Creative Commons Attribution-ShareAlike.

43 J. Berzelius, Jahres-Bericht, 1841, 20, 7.

44 J. Berzelius, Jahres-Bericht, 1832(11), 44.

45 O. Lehmann, Z. Krist., 1874(1), 97.

46 O. Lehmann, Molekularphysik, 1888, 2, 398.

47 W. B. Jensen, J. Chem. Educ., 2006, 83(6), 838.

48 W. Ostwald, Outlines of General Chemistry, 1912, 104.

49 G. J. Leigh, Nomenclature of Inorganic Chemistry, Blackwell, Oxford, 1990.

50 M. Nič, J. Jirát, B. Košata, A. Jenkins and A. McNaught, IUPAC Compendium of Chemical Terminology, 2009.

51 M. Nič, J. Jirát, B. Košata, A. Jenkins and A. McNaught, Allotropic transition: Compendium of Chemical Terminology, IUPAC, Research Triagle Park, NC, 2009.

52 M. Nič, J. Jirát, B. Košata, A. Jenkins and A. McNaught, IUPAC Compendium of Chemical Terminology, 2009.

53 A. Hirsch, Nat. Mater., 2010, 9(11), 868. 
54 J. M. Zazula, On Graphite Transformations at High Temperature and Pressure Induced by Absorption of the LHC Beam: (c)1997 CERN, LHC Project-Note-78.

55 O. M. Yaghi, M. O’Keeffe, N. W. Ockwig, H. K. Chae, M. Eddaoudi and J. Kim, Nature, 2003, 423(6941), 705.

56 A. K. Geim and K. S. Novoselov, Nat. Mater., 2007, 6(3), 183.

57 Q. Li, Z. Li, M. Chen and Y. Fang, Nano Lett., 2009, 9(5), 2129.

58 C. S. Barrett, Structure of metals: Crystallographic methods, principles, and data, Horney Press, 2010.

59 R. A. Flinn and P. K. Trojan, Engineering materials and their applications, Wiley, New York, Chichester, 1995.

60 P. G. Caceres, Engineering Materials for Electrical Engineers, used under a Creative Commons Attribution-ShareAlike, Valencia.

61 B. S. Mitchell, An introduction to materials engineering and science for chemical and materials engineers, 389, John Wiley, Hoboken, NJ, 2004.

62 F. C. Campbell, Elements of metallurgy and engineering alloysp. 154, ASM International, Materials Park, Ohio, 2008.

63 R. E. Smallman and R. J. Bishop, Modern physical metallurgy, p. 282, Butterworth-Heinemann, Boston, 1999.

64 M. P. Groover, Principles of modern manufacturing, p. 658, John Wiley \& Sons, Hoboken, NJ, 2011.

65 C. Dang Ngoc Chan, Steel phase diagram Iron-carbon phase diagram under atmospheric pressure, used under a Creative Commons Attribution-ShareAlike.

66 Metallurgical Consultants, Schematic of Time Temperature Transformation Diagram, 2012, http://www.materialsengineer.com/E-Steel\%20Properties\%20Overview.htm.

67 C. R. Brooks, Principles of Heat Treatment of Plain Carbon and Low Alloy Steels, ASM International, 1996.

68 G. A. Rinne, Adv. Packag., 2006, 15(9), 32-34.

69 Y. Kariya, C. Gagg and W. J. Plumbridge, Soldering Surf. Mount Technol., 2001, 13(1), 39.

70 H. Pniok, Tin / Heinrich Pniok - Periodensystem der Chemischen Elemente used under a Creative Commons Attribution-ShareAlike.

71 M. Leodolter-Dworak, I. Steffan, W. J. Plumbridge and H. Ipser, J. Electron. Mater., 2010, 39(1), 105.

72 E. Brillas, E. B. Coso and P. L. Cabot, Trends in Electrochemistry and Corrosion at the Beginning of the 21st Century: Dedicated to Professor Dr Josep M. Costa on the Occasion of His 70th Birthday, pp. 1218-1219, Universitat, 2004.

73 B. Weintraub, Bull. Isr. Chem. Soc., 2002(9), 31.

74 C. W. Mason and W. D. Forgeng, Met. Alloys, 1935, 6, 87.

75 D. E. Patterson and J. L. Margrave, J. Phys. Chem., 1990, 94(3), 1094.

76 A. J. Moulson and J. M. p. Herbert, Electroceramics: Materials, Properties, Applications, Wiley, 2003.

77 R. M. Parker, Dent Today, 2007, 26(3), 114-116 quiz 119, 112.

78 R. H. J. Hannink, P. M. Kelly and B. C. Muddle, J. Am. Ceram. Soc., 2000, 83(3), 461.

79 V. S. R. Murthy, Structure And Properties of Engineering Materials, p. 167, McGraw-Hill Education (India) Pvt Limited, 2003.
80 V. Srikanth and E. C. Subbarao, J. Mater. Sci., 1994, 29(12), 3363.

81 University of Cambridge, Vacancy transportin YSZ, used under a Creative Commons Attribution-ShareAlike, 20042012.

82 A. H. Heuer, J. Am. Ceram. Soc., 1987, 70(10), 689.

83 D. M. Stump and B. Budiansky, Crack-growth resistance in transformation-toughened ceramics, Harvard Univ, 1989.

84 W. R. Cannon, Treatise Mater. Sci. Technol., 1989, 29(Struct Ceram), 195.

85 T. Y. Tien, Toughened zirconia-based ceramics (US4886768A), University of Michigan, USA, 1989.

86 G. Hamilton, Blue Planet: Earth, p. 3, Milliken Publishing Company, 2007.

87 A. Navrotsky, Physics and Chemistry of Earth Materials, p. 303, Cambridge University Press, 1994.

88 G. R. Helffrich and B. J. Wood, Nature, 2001, 412(6846), 501.

89 A. M. Dziewonski and D. L. Anderson, Phys. Earth Planet. Inter., 1981, 25(4), 297.

90 N. C. Schmerr, 2012, http://www.dtm.ciw.edu/users/ nschmerr/site/Research.html.

91 A. E. Ringwood and A. Major, Phys. Earth Planet. Inter., 1970, 3, 89.

92 E. Ito and E. Takahashi, J. Geophys. Res., 1989, 94(B8), 10637.

93 L.-G. Liu, Nature, 1976, 262(5571), 770.

94 U. Christensen, Annu. Rev. Earth Planet. Sci., 1995, 23, 65.

95 M. Murakami, Science, 2004, 304(5672), 855.

96 R. S. McWilliams, D. K. Spaulding, J. H. Eggert, P. M. Celliers, D. G. Hicks, R. F. Smith, G. W. Collins and R. Jeanloz, Science, 2012, 338(6112), 1330.

97 W. J. Zhang, Y. L. Sun, K. Neil, Y. Lei and Z. Li, Eur. Phys. J. Plus, 2011, 126(3), 31-12.

98 A. J. Biggin, B. Steinberger, J. Aubert, N. Suttie, R. Holme, T. H. Torsvik, d. M. D. G. van and H. D. J. J. van, Nat. Geosci., 2012, 5(9), 674.

99 C. Salzmann, P. Radaelli, E. Mayer and J. Finney, Phys. Rev. Lett., 2009, 103(10).

100 F. Franks, Water: 2nd edition: A matrix of life, Royal Society of Chemistry, London, 2000.

101 C. G. Salzmann, P. G. Radaelli, B. Slater and J. L. Finney, Phys. Chem. Chem. Phys., 2011, 13(41), 18468.

102 G. Vigier, G. Thollet and R. Vassoille, J. Cryst. Growth, 1987, 84(2), 309.

103 H. Konig, Z. Kristallogr., Kristallgeom., Kristallphys., Kristallchem., 1944, 105, 279.

104 M. Dymarska, B. J. Murray, L. Sun, M. L. Eastwood, D. A. Knopf and A. K. Bertram, J. Geophys. Res., 2006, 111(D4).

105 B. P. Chekal, A. M. Campeta, Y. A. Abramov, N. Feeder, P. P. Glynn, R. W. McLaughlin, P. A. Meenan and R. A. Singer, Org. Process Res. Dev., 2009, 13(6), 1327.

106 J. Wilbrand, Justus Liebigs Ann. Chem., 1863, 128(2), 178.

107 A. Thompson and B. N. Taylor, The NIST Guide for the use of the International System of Units: B. 8 Factors for Units Listed Alphabetically, http://www.nist.gov/pml/pubs/sp811/ index.cfm, 2008.

108 T. Ito, R. Sadanaga and Y. Takeuchi, X-Ray Studies on Polymorphism, Maruzen Co, 1950. 
109 L. A. Burkardt and J. H. Bryden, Acta Crystallogr., 1954, 7(1), 135.

110 R. M. Vrcelj, J. N. Sherwood, A. R. Kennedy, H. G. Gallagher and T. Gelbrich, Cryst. Growth Des., 2003, 3(6), 1027.

111 T. N. Drebushchak and E. V. Boldyreva, Z. Kristallogr., 2004, 219(8-2004), 506.

112 H. G. Gallagher, K. J. Robers, J. N. Sherwood and L. A. Smith, J. Mater. Chem., 1997, 7(2), 229.

113 H. G. Gallagher and J. N. Sherwood, J. Chem. Soc., Faraday Trans., 1996, 92(12), 2107.

114 H. G. Gallagher, R. M. Vrcelj and J. N. Sherwood, J. Cryst. Growth, 2003, 250(3-4), 486.

115 R. M. Vrcelj, H. G. Gallagher and J. N. Sherwood, J. Am. Chem. Soc., 2001, 123(10), 2291.

116 W. Sneader, Br. Med. J., 2000, 321(7276), 1591.

117 P. J. Wheatley, J. Chem. Soc., 1964, 6036.

118 P. Vishweshwar, J. A. McMahon, M. Oliveira, M. L. Peterson and M. J. Zaworotko, J. Am. Chem. Soc., 2005, 127(48), 16802.

119 A. D. Bond, R. Boese and G. R. Desiraju, Angew. Chem., Int. Ed., 2007, 46(4), 615.

120 A. D. Bond, R. Boese and G. R. Desiraju, Angew. Chem., Int. Ed., 2007, 46(4), 618.

121 T. Beyer and S. L. Price, J. Phys. Chem. B, 2000, 104(12), 2647.

122 M. C. Etter, Acc. Chem. Res., 1990, 23(4), 120.

123 T. Li, J. Pharm. Sci., 2007, 96(4), 755.

124 E. J. Chan, T. R. Welberry, A. P. Heerdegen and D. J. Goossens, Acta Crystallogr., Sect. B: Struct. Sci., 2010, 66(6), 696.

125 M. Haisa, S. Kashino, R. Kawai and H. Maeda, Acta Crystallogr., Sect. B: Struct. Crystallogr. Cryst. Chem., 1976, 32(4), 1283.

126 A. Burger, Acta Pharm. Technol., 1982, 28(1), 1.

127 E. Joiris, P. Di Martino, C. Berneron, A. Guyot-Hermann and J. Guyot, Pharm. Res., 1998, 15(7), 1122.

128 H. Garekani, Int. J. Pharm., 1999, $187(1), 77$.

129 H. A. Garekani, J. L. Ford, M. H. Rubinstein and A. R. Rajabi-Siahboomi, Drug Dev. Ind. Pharm., 2001, 27(9), 935.

130 J. B. Nanubolu and J. C. Burley, Mol. Pharmaceutics, 2012, 9(6), 1544.

131 S. Gaisford, A. B. Buanz and N. Jethwa, J. Pharm. Biomed. Anal., 2010, 53(3), 366.

132 P. Martino, P. Conflant, M. Drache, J.-P. Huvenne and A.M. Guyot-Hermann, J. Therm. Anal., 1997, 48(3), 447.

133 D. Craig, Int. J. Pharm., 1999, 179(2), 179.
134 F. N. de Wet, J. J. Gerber, A. P. Lotter, J. G. van der Watt and T. G. Dekker, Drug Dev. Ind. Pharm., 1998, 24(5), 447.

135 J. C. Burley, M. J. Duer, R. S. Stein and R. M. Vrcelj, Eur. J. Pharm. Sci., 2007, 31(5), 271.

136 M.-A. Perrin, M. A. Neumann, H. Elmaleh and L. Zaske, Chem. Commun., 2009(22), 3181.

137 M. Sacchetti, J. Therm. Anal. Calorim., 2001, 63(2), 345.

138 A. R. Choudhury, K. Islam, M. T. Kirchner, G. Mehta and T. N. Guru Row, J. Am. Chem. Soc., 2004, 126(39), 12274.

139 M. Karanam, S. Dev and A. R. Choudhury, Cryst. Growth Des., 2012, 12(1), 240.

140 M. R. Caira, K. A. Alkhamis and R. M. Obaidat, J. Pharm. Sci., 2004, 93(3), 601.

141 B. Moulton and M. J. Zaworotko, Chem. Rev., 2001, 101(6), 1629.

142 C. E. Housecroft and A. G. Sharpe, Inorganic chemistry, Pearson Prentice Hall, Upper Saddle River, N.J., 2005.

143 S. Takamizawa, T. Akatsuka and T. Ueda, Angew. Chem., Int. Ed., 2008, 47(9), 1689.

144 T. Ueda, G. M. Bernard, R. McDonald and R. E. Wasylishen, Solid State Nucl. Magn. Reson., 2003, 24(2-3), 163.

145 J. D. Dunitz, Acta Crystallogr., Sect. B: Struct. Sci., 1995, 51(4), 619.

146 P. Seiler and J. Dunitz, Acta Crystallogr., Sect. B: Struct. Crystallogr. Cryst. Chem., 1979, 35(9), 2020.

147 J. P. Fackler Jnr, R. J. Staples, M. N. I. Khan and R. E. P. Winpenny, Acta Crystallogr., Sect. C: Cryst. Struct. Commun., 1994, 50(7), 1020.

148 D. Braga, F. Grepioni, M. Polito, M. R. Chierotti, S. Ellena and R. Gobetto, Organometallics, 2006, 25(19), 4627.

149 D. Braga, M. Polito, D. D’Addario and F. Grepioni, Cryst. Growth Des., 2004, 4(6), 1109.

150 C. Janiak, Dalton Trans., 2003(14), 2781.

151 K. M. Fromm, J. L. S. Doimeadios and A. Y. Robin, Chem. Commun., 2005(36), 4548.

152 G.-H. Lee and H.-T. Wang, Molecules, 2006, 11(8), 589.

153 A. Y. Robin, J. L. Sague Doimeadios, A. Neels, T. Vig Slenters and K. M. Fromm, Inorg. Chim. Acta, 2007, 360(1), 212.

154 X.-D. Chen, M. Du and T. C. W. Mak, Chem. Commun., 2005(35), 4417.

155 M. Wriedt, I. Jeß and C. Näther, Eur. J. Inorg. Chem., 2009, 2009(3), 363.

156 A. Cingolani, S. Galli, N. Masciocchi, L. Pandolfo, C. Pettinari and A. Sironi, J. Am. Chem. Soc., 2005, $127(17), 6144$. 